\title{
Synergistic Actions of Blocking Angiopoietin-2 and Tumor Necrosis Factor- $\alpha$ in Suppressing Remodeling of Blood Vessels and Lymphatics in Airway Inflammation
}

\author{
Catherine T.K. Le, ${ }^{* \dagger}$ Grace Laidlaw, ${ }^{* \dagger}$ Christopher A. Morehouse, ${ }^{\ddagger}$ Brian Naiman, ${ }^{\dagger \dagger}$ Philip Brohawn, ${ }^{\ddagger}$ Tomas Mustelin,
} Jane R. Connor, and Donald M. McDonald ${ }^{*}$

From the Department of Anatomy,* Cardiovascular Research Institute, and University of California San Francisco Helen Diller Family Comprehensive Cancer Center, ${ }^{\dagger}$ University of California San Francisco, San Francisco, California; and MedImmune LLC, ${ }^{\ddagger}$ Gaithersburg, Maryland

\author{
Accepted for publication \\ July 23, 2015. \\ Address correspondence to \\ Donald M. McDonald, M.D., \\ Ph.D., University of California, \\ San Francisco, 513 Parnassus \\ Ave, Room S1349, San Fran- \\ cisco, CA 94143-0452. E-mail: \\ donald.mcdonald@ucsf.edu.
}

\begin{abstract}
Remodeling of blood vessels and lymphatics are prominent features of sustained inflammation. Angiopoietin-2 (Ang2)/Tie2 receptor signaling and tumor necrosis factor- $\alpha$ (TNF)/TNF receptor signaling are known to contribute to these changes in airway inflammation after Mycoplasma pulmonis infection in mice. We determined whether Ang2 and TNF are both essential for the remodeling on blood vessels and lymphatics, and thereby influence the actions of one another. Their respective contributions to the initial stage of vascular remodeling and sprouting lymphangiogenesis were examined by comparing the effects of function-blocking antibodies to Ang2 or TNF, given individually or together during the first week after infection. As indices of efficacy, vascular enlargement, endothelial leakiness, venular marker expression, pericyte changes, and lymphatic vessel sprouting were assessed. Inhibition of Ang2 or TNF alone reduced the remodeling of blood vessels and lymphatics, but inhibition of both together completely prevented these changes. Genome-wide analysis of changes in gene expression revealed synergistic actions of the antibody combination over a broad range of genes and signaling pathways involved in inflammatory responses. These findings demonstrate that Ang2 and TNF are essential and synergistic drivers of remodeling of blood vessels and lymphatics during the initial stage of inflammation after infection. Inhibition of Ang2 and TNF together results in widespread suppression of the inflammatory response.
\end{abstract}

(Am J Pathol 2015, 185: 2949-2968; http://dx.doi.org/10.1016/j.ajpath.2015.07.010)
Remodeling of blood vessels and lymphatics contributes to the pathophysiology of many chronic inflammatory diseases, including asthma, chronic bronchitis, chronic obstructive pulmonary disease, inflammatory bowel disease, and psoriasis. ${ }^{1-3}$ When inflammation is sustained, capillaries acquire venule-like properties that expand the sites of plasma leakage and leukocyte influx. Consistent with this transformation, the remodeled blood vessels express P-selectin, intercellular adhesion molecule 1 (ICAM-1), EphB4, and other venular markers. ${ }^{4-6}$ The changes are accompanied by remodeling of pericytes and disruption of pericyte-endothelial crosstalk involved in blood vessel quiescence. Remodeling of blood vessels is accompanied by plasma leakage, inflammatory cell influx, and sprouting lymphangiogenesis. $6,8,9$

Mycoplasma pulmonis infection causes sustained inflammation of the respiratory tract of rodents. ${ }^{10}$ This infection has

\footnotetext{
Supported, in part, by the National Heart, Lung, and Blood Institute/NIH grants P01 HL024136, R01 HL059157, and R01 HL127402; a MedImmune LLC grant; and AngelWorks Foundation funding (D.M.McD.).

C.T.K.L. and G.L. contributed equally to this work.

Disclosures: C.A.M., B.N., P.B., T.M., and J.R.C. are employees of MedImmune LLC, a wholly owned subsidiary of AstraZeneca, and are holders of company stock or stock options. MedImmune LLC supplied antiAng2, clone 3.19.3, AZD5180, and anti-TNF- $\alpha$, MP6-XT22, which was purchased from BioLegend (San Diego, CA).

Current address of C.T.K.L., University of California-Davis Medical School, Davis, CA; of G.L., Stanford Medical School, Stanford, CA.
} 
proved useful for dissecting the features and mechanisms of vascular remodeling and lymphangiogenesis. ${ }^{6,9,10}$ At 7 days after infection, there is widespread conversion of capillaries into venules, pericyte remodeling, inflammatory cell influx, and lymphatic vessel sprouting in the airways and lung. ${ }^{4-9}$ Many features of chronic M. pulmonis infection in mice are similar to Mycoplasma pneumoniae infection in humans. ${ }^{11}$

Angiopoietin-2 (Ang2) is a context-dependent antagonist of Tie2 receptors ${ }^{12,13}$ that is important for prenatal and postnatal remodeling of blood vessels and lymphatic vessels. ${ }^{13-15}$ Ang2 promotes vascular remodeling, ${ }^{4,5}$ lymphangiogenesis, ${ }^{15-17}$ and pericyte $\operatorname{loss}^{18}$ in disease models in mice. Mice genetically lacking Ang2 have less angiogenesis, lymphangiogenesis, and neutrophil recruitment in inflammatory bowel disease. ${ }^{3}$ Ang2 has proved useful as a plasma biomarker of endothelial cell activation in acute lung injury, sepsis, hypoxia, and cancer. ${ }^{19}$

Like Ang2, tumor necrosis factor (TNF)- $\alpha$ is a mediator of remodeling of blood vessels and lymphatics. ${ }^{8,9,20,21}$ TNF triggers many components of the inflammatory response, including up-regulation of expression of vascular cell adhesion molecule-1, ICAM-1, and other endothelial cell adhesion molecules. ${ }^{22}$ TNF inhibitors reduce inflammation in mouse models of inflammatory disease ${ }^{23,24}$ and are used clinically in the treatment of rheumatoid arthritis, ankylosing spondylitis, Crohn's disease, psoriatic arthritis, and some other inflammatory conditions. ${ }^{24,25}$ Indicative of the complex role of TNF in disease, inhibition or deletion of TNF can increase the risk of serious infection by bacterial, mycobacterial, fungal, viral, and other opportunistic pathogens. $^{26}$

TNF and Ang2 interact in inflammatory responses. TNF increases Ang2 expression in endothelial cells in a time- and dose-dependent manner, both in blood vessels ${ }^{27}$ and lymphatics. ${ }^{16}$ Administration of TNF with Ang2 increases cell adhesion molecule expression more than TNF alone. ${ }^{16,28}$ Similarly, Ang2 can promote corneal angiogenesis in the presence of TNF, but not alone. ${ }^{29}$ In mice that lack Ang2, TNF induces leukocyte rolling but not adherence to the endothelium. ${ }^{28}$ Ang2 also augments TNF production by macrophages. ${ }^{30,31}$ Inhibition of Ang2 and TNF together with a bispecific antibody can ameliorate rheumatoid arthritis in a mouse model. ${ }^{32}$

With this background, we sought to determine whether Ang2 and TNF act together to drive the remodeling of blood vessels and lymphatics in the initial inflammatory response to $M$. pulmonis infection. In particular, we asked whether Ang2 and TNF have synergistic actions in this setting. The approach was to compare the effects of selective inhibition of Ang2 or TNF, individually or together, and then assess the severity of vascular remodeling, endothelial leakiness, venular marker expression, pericyte changes, and lymphatic sprouting. Functional consequences of genome-wide changes in gene expression were analyzed by Ingenuity Pathway Analysis (IPA) ${ }^{33,34}$ and the Database for Annotation, Visualization and Integrated Discovery (DAVID). ${ }^{35}$ The studies revealed that inhibition of Ang2 and TNF together, but not individually, completely prevented the development of vascular remodeling and lymphatic sprouting and had synergistic effects in suppressing gene expression and cellular pathways activated during the initial stage of the inflammatory response.

\section{Materials and Methods}

Mice

Female 8-week-old C57BL/6 mice (Charles River, Hollister, $\mathrm{CA}$; or Jackson Laboratory, Bar Harbor, MN), housed under barrier conditions, were used for all experiments. All experimental procedures were approved by the Institutional Animal Care and Use Committee of the University of California, San Francisco.

\section{M. pulmonis Infection}

Mice were anesthetized with an i.m. injection of $10 \mathrm{mg} / \mathrm{kg}$ ketamine and $20 \mathrm{mg} / \mathrm{kg}$ xylazine and inoculated intranasally with $50 \mu \mathrm{L}$ culture media containing $1 \times 10^{6}$ colonyforming units of M. pulmonis (strain CT8), divided as 25 $\mu \mathrm{L}$ into each nostril. ${ }^{4,9}$ Mice were studied 7 days after infection.

\section{Function-Blocking Antibodies}

Function-blocking monoclonal human anti-Ang2 antibody (anti-Ang2; clone 3.19.3; AZD5180; $10 \mathrm{mg} / \mathrm{kg}$; MedImmune LLC, Gaithersburg, MD) ${ }^{5,36}$ and/or monoclonal rat anti-murine TNF antibody (anti-TNF; MP6-XT22; $3 \mathrm{mg} / \mathrm{kg}$; BioLegend, San Diego, CA) ${ }^{37,38}$ was injected i.p. into mice every other day for 7 days, beginning 1 day before infection. Corresponding controls received injections of normal human $\mathrm{IgG}$ and/or normal rat $\mathrm{IgG}$ or phosphate-buffered saline (PBS).

\section{Immunohistochemistry}

Anesthetized mice were perfused for 2 minutes with $1 \%$ paraformaldehyde in PBS, $\mathrm{pH} 7.4$, through a cannula inserted through the left ventricle. ${ }^{4,9}$ Tracheas were removed, immersed in $1 \%$ paraformaldehyde for 1 hour, and then incubated overnight in combinations of two or three of the following primary antibodies, diluted in a mixture of $0.3 \%$ Triton X-100 (Sigma-Aldrich, St. Louis, MO), $0.2 \%$ bovine serum albumin, and $0.1 \%$ sodium azide in PBS containing 10\% goat serum: platelet endothelial cell adhesion molecule (PECAM-1; hamster anti-mouse CD31, clone 2H8, 1:500; Thermo Fisher Scientific, Waltham, MA), lymphatic vessel endothelial hyaluronan receptor-1 (rabbit anti-mouse lymphatic vessel endothelial hyaluronan receptor-1, catalog number 11-034, 1:500; AngioBio, Del Mar, CA), desmin (rabbit anti-mouse desmin, clone Y66, 1:500; Thermo Fisher Scientific), P-selectin (rat anti-mouse CD62P, 
RB40.34; $1 \mathrm{mg} / \mathrm{mL}$; BD Biosciences, San Diego, CA), or S100a9 (rat anti-mouse S100a9, 2B10; 1:500; Abcam, Cambridge, England). Tracheas were incubated overnight in secondary antibodies conjugated to Alexa Fluor-488, Cy3, or Alexa Fluor-647 (all used at 1:500; Jackson ImmunoResearch, West Grove, PA), fixed for 5 minutes in $1 \%$ paraformaldehyde, and mounted as whole mounts.

\section{Microscopic Imaging}

Digital images were acquired with a Zeiss Axiophot fluorescence microscope (Carl Zeiss Microscopy GmbH, Jena, Germany) equipped with single- and dual-fluorescence filters and a low-light, three-chip, charge-coupled device camera $(480 \times 640$-pixel RGB-color images; CoolCam; SciMeasure Analytical Systems, Atlanta, GA) and linked to a digitizing tablet (Digi-Pad; GTCO CalComp, Columbia, MD). Confocal digital images were obtained with a Zeiss LSM-510 confocal microscope equipped (Carl Zeiss Microscopy $\mathrm{GmbH}$ ) with argon and helium-neon lasers, using AIM software version 3.2.2.

\section{Morphometric Analysis}

The diameter of blood vessels was measured in tracheal whole mounts stained for PECAM-1. Measurements were made of mucosal vessels specifically overlying the rostrocaudal midpoint of cartilage rings, which in normal tracheas consisted only of capillaries that were located approximately halfway between the arteriole and venule. ${ }^{5,7,8}$ The diameter of 15 vessels was measured over each of five cartilage rings per trachea. To assess the status of pericytes, the number of cytoplasmic processes of pericytes was determined in the same regions as the vessels in tracheal whole mounts stained for desmin and PECAM-1. Pericyte processes were defined as desmin-positive extensions of the cell body. Processes on 20 pericytes were counted on vessels over each of five to eight cartilage rings per trachea. Remodeling of lymphatics for lymphatic vessel endothelial hyaluronan receptor-1 was evaluated by counting sprouts (tapered projections) from lymphatic vessels $(10 \times$ objective, $1 \times$ Optovar; Carl Zeiss Microscopy GmbH). Sprouts were counted in five regions, each having an area of 0.53 $\mathrm{mm}^{2}$, in each trachea. Values were expressed per square millimeter of tracheal mucosa. Measurements were made with a digitizing tablet on real-time images viewed on a computer monitor displaying the output of the fluorescence microscope (see Microscopic Imaging).

\section{Measurement of Vascular Leakage}

Unanesthetized mice received, by tail vein injection, 50 $\mu \mathrm{L}$ of Dragon-Green 50-nm fluorescent polystyrene microspheres (1\% solids; Bangs Laboratories, Inc., Fishers, IN). ${ }^{7,39}$ Mice were anesthetized 6 minutes later with 10 $\mathrm{mg} / \mathrm{kg}$ ketamine and $20 \mathrm{mg} / \mathrm{kg}$ xylazine injected i.m., and were perfused with fixative 10 minutes after injection of microspheres. The vasculature was stained for PECAM-1. Digital images of regions of tracheal mucosa, measuring $960 \times 2244 \mu \mathrm{m}$ over five to eight cartilage rings, starting from the rostral end, were taken with the fluorescence microscope $(10 \times$ objective, $1 \times$ Optovar $)$. Regions of posterior membrane were excluded. Leakage was assessed by measuring extravasated fluorescent microspheres in regions of tracheal mucosa over cartilage rings. ${ }^{7,39}$ The fractional area (area density) was calculated as the proportion of pixels with a fluorescence intensity value (range, $0>255$ ) equal to or greater than the threshold of 30 by using ImageJ software version $1.46(\mathrm{NIH}$, Bethesda, MD; http://imagej.nih.gov/ij). The overall mean for each group was calculated from the average of all values for each mouse ( $N=9$ to 11 mice per group).

\section{Measurement of Neutrophil Recruitment}

S100a9 immunofluorescence was measured in digital images of regions of tracheal mucosa, measuring $1300 \times 1300 \mu \mathrm{m}$, over cartilage rings where vascular remodeling after infection was greatest. ${ }^{5,8}$ Five regions were assessed in each tracheal whole mount, beginning with the third cartilage ring caudal to the larynx and continuing consecutively toward the bifurcation. Area density of S100a9 immunofluorescence was calculated as the proportion of pixels with a fluorescence intensity value (range, $0>255$ ) equal to or greater than the threshold of 80 determined with ImageJ software. The overall mean for each group was calculated from the average of all values for each mouse ( $N=4$ to 9 mice per group).

\section{Analysis of 48 Selected Genes in Tracheas by Dynamic Array Chips}

Tracheas of anesthetized pathogen-free mice, mice treated with vehicle during 7-day infection with M. pulmonis (infected vehicle), and infected mice treated with anti-Ang2 antibody, anti-TNF antibody, or both antibodies (antibody combination) were excised after vascular perfusion with PBS for 30 seconds and snap frozen in liquid nitrogen (four mice each in pathogen-free and antibody combination groups and five mice in each of the other groups). Total RNA was extracted using the RNeasy Fibrous Tissue Kit (Qiagen Inc., Valencia, CA), following manufacturer's instructions. RNA purity and concentration were determined spectrophotometrically; quality was confirmed on selected samples using the RNA 6000 Nano LabChip and an Agilent 2100 Bioanalyzer (Agilent Technologies Inc., Santa Clara, CA). cDNA was generated from total RNA using the SuperScript III First Strand Synthesis Super Mix (Invitrogen, Carlsbad, CA).

cDNA was pre-amplified using TaqMan Pre-Amp Master Mix (Thermo Fisher Scientific), according to the manufacturer's instructions. Reactions contained $2.5 \mu \mathrm{L}$ cDNA, $5 \mu \mathrm{L}$ Pre-Amp Master Mix, and $2.5 \mu \mathrm{L}$ of $0.2 \times$ gene expression assay mix (containing all probes to be assessed) for a final 
Table 1 Gene Number (Percentage) That Met Selection Criteria for Analysis

\begin{tabular}{|c|c|c|c|c|c|c|}
\hline $\begin{array}{l}\text { Gene selection } \\
\text { method }\end{array}$ & $\begin{array}{l}\text { Infection-related } \\
\text { change }\end{array}$ & $\begin{array}{l}\text { Treatment-related } \\
\text { change }\end{array}$ & $\begin{array}{l}\text { Infected } \\
\text { vehicle* }^{*}\end{array}$ & $\begin{array}{l}\text { Anti-Ang2 } \\
\text { antibody* }\end{array}$ & $\begin{array}{l}\text { Anti-TNF } \\
\text { antibody* }\end{array}$ & Antibody combination* \\
\hline \multicolumn{7}{|l|}{ Method No. 1} \\
\hline Condition B & Increase & Increase & & $134(34)$ & $126(10)$ & $383(21)$ \\
\hline Condition C & Decrease & Increase & $3512(46)$ & $46(12)$ & $268(20)$ & $416(22)$ \\
\hline Condition D & Decrease & Decrease & & $96(24)$ & $12(1)$ & $61(3)$ \\
\hline Condition A & Increase & Decrease & $3864(46)$ & $119(14)$ & $855(50)$ & $946(39)$ \\
\hline Condition B & Increase & Increase & & $239(29)$ & $154(9)$ & $482(20)$ \\
\hline Condition C & Decrease & Increase & $4497(54)$ & $76(9)$ & $523(31)$ & $711(29)$ \\
\hline \multirow[t]{2}{*}{ Condition D } & Decrease & Decrease & & $396(48)$ & $178(10)$ & $299(12)$ \\
\hline & & Total & $8361(100)$ & $830(100)$ & $1710(100)$ & $2438(100)$ \\
\hline
\end{tabular}

Values from Affymetrix GeneChip arrays were obtained from tracheas of five groups of mice: pathogen-free, infected with Mycoplasma pulmonis for 7 days and treated with vehicle, and infected and treated with anti-Ang2 antibody, anti-TNF antibody, or both antibodies (antibody combination) ( $N=4$ to 5 mice per group). Method 1 was used to assess the overall effect of the treatments, identify genes that underwent large or small changes in expression during infection and treatment, and analyze changes in signaling pathways by the Database for Annotation, Visualization and Integrated Discovery (DAVID). Probe sets were selected that had at least $25 \%$ increase or decrease in expression in the infected vehicle group relative to the pathogen-free group; then, the subset of these probe sets was selected for each treatment group that had $50 \%$ or more suppression or amplification in expression compared with the infected vehicle group. Selected probe sets in infected vehicle group met the first criterion, and those in the three treatment groups met both criteria. The direction of the two changes defined conditions A, B, C, and D. Method 2 was used to analyze changes in signaling pathways by Ingenuity Pathway Analysis (IPA). As described in Materials and Methods, probe sets selected for analysis by IPA satisfied multiple criteria, including $>10 \%$ difference from the pathogen-free group and $50 \%$ or greater change in any treatment group from the infected vehicle group.

${ }^{*}$ Data are given as number (percentage).

Ang2, angiopoietin-2; TNF, tumor necrosis factor.

volume of $10 \mu \mathrm{L}$. Reactions were cycled 14 times, then diluted with $80 \mu \mathrm{L}$ DNA suspension buffer (Teknova, Hollister, CA). The samples were prepared for loading into $48 \times 48$ Dynamic Array Chips (Fluidigm Corp., South San Francisco, CA) by mixing $2.5 \mu \mathrm{L} 2 \times$ Universal Master Mix (Applied Biosystems, Carlsbad, CA), $0.25 \mu \mathrm{L}$ Sample Loading Buffer (Fluidigm Corp.), and $2.25 \mu \mathrm{L}$ pre-amplified cDNA. The probes were prepared by mixing $3 \mu \mathrm{L} 20 \times$ TaqMan Gene Expression Assay (Invitrogen) with $3 \mu \mathrm{L}$ Assay Loading Buffer (Fluidigm Corp.). The chip was primed in the IFC Controller (Fluidigm Corp.), then $5 \mu \mathrm{L}$ of prepared sample was loaded into the sample inlets of the dynamic array chip in duplicate, and $5 \mu \mathrm{L}$ of the $10 \times$ gene expression assay mix was loaded into the detector inlets. The chip was then placed back in the IFC Controller for loading and mixing. Finally, the chip was placed in the BioMark Real-Time PCR System (Fluidigm Corp.) for thermal cycling $\left(95^{\circ} \mathrm{C}\right.$ for 10 minutes, followed by 40 cycles of $95^{\circ} \mathrm{C}$ for 15 seconds and $60^{\circ} \mathrm{C}$ for 1 minute). The $\mathrm{Ct}$ values were normalized to the average $\mathrm{Ct}$ values of $\beta$-actin and $\beta 2$ microglobulin, then normalized to the average of the pathogen-free mouse group and expressed as relative fold change.

\section{Genome-Wide Analysis of Gene Expression in Tracheas by GeneChip Arrays}

RNA from the five groups of mouse tracheal samples used for analysis by Dynamic Array Chips was also used for Affymetrix (Santa Clara, CA) GeneChip analysis. Biotin-labeled sequences for hybridization to Affymetrix Mouse 430 2.0 GeneChip arrays were prepared with the SuperScript double-stranded
cDNA synthesis kit (Life Technologies, Carlsbad, CA) and the IVT Labeling Kit (Affymetrix, Santa Clara, CA), following standard hybridization, washing and staining, and scanning procedures. Array data were processed using the frozen robust multiarray analysis algorithm ${ }^{33}$ in $\mathrm{R}$ programming language (http://www.r-project.org) for statistical computing (frozen robust multiarray analysis package) to obtain normalized and summarized expression values. Data were filtered to remove probe sets with a maximum linear scale expression intensity $<25$ across all samples. The mean linear scale expression for each probe set was calculated for each treatment group. Differences among the five groups were assessed by the following two methods.

Method 1 was used to assess the overall effect of the treatments, identify genes that underwent especially large or small changes in expression during infection and treatment, and analyze functional consequences of the gene expression changes by DAVID. ${ }^{35}$ With this method, genes were selected by two criteria from among 31,944 annotated probe sets on the array: probe sets that had at least a $25 \%$ increase or decrease in expression in the infected vehicle group compared with the pathogen-free group, and the subset of these probe sets that had $50 \%$ or more suppression or amplification of expression by one or more treatments relative to the infected vehicle group. These criteria defined four scenarios, designated condition $\mathrm{A}, \mathrm{B}, \mathrm{C}$, or $\mathrm{D}$, on the basis of whether expression was increased or decreased by infection and whether this change was suppressed or amplified by treatment (Table 1).

Expression of nearly 8000 annotated genes changed by $>25 \%$ during infection, with approximately half changing in each direction (Table 1). Increased expression during 
infection defined conditions $\mathrm{A}$ and $\mathrm{B}$, which were distinguished by $>50 \%$ treatment-related increase (condition $\mathrm{A}$ ) or decrease (condition B) (Table 1). Decreased expression during infection with corresponding treatment effects defined conditions C and D (Table 1). More than $90 \%$ of genes that had large (more than fivefold) increases in expression during infection were in condition A. Fewer than $10 \%$ were in condition B. Similarly, $>90 \%$ of genes that decreased in expression to $<20 \%$ of the pathogen-free level were in condition $\mathrm{C} ;<10 \%$ were in condition $\mathrm{D}$. Accordingly, condition A genes were examined to assess treatment-induced suppression of increased expression during infection, and condition $\mathrm{C}$ genes were examined to assess the prevention of decreased expression during infection (Table 1).

Method 2 was used to analyze changes in signaling pathways by the IPA tool (Qiagen, Redwood City, CA; http://www.qiagen.com/ingenuity; last accessed June 19, 2015). ${ }^{33,34}$ With this method, mean adjusted expression values were calculated for each of the 45,101 probe sets on the array by subtracting the mean expression intensity for the pathogen-free group from the mean expression intensity of each of the other four groups. To minimize the impact of small (between -1 and 1) expression differentials, the values were pedestaled by subtracting 1 from values $<0$ and adding 1 to values $>0$. To reduce the potential for misinterpreting small differences relative to the pathogen-free group, probe sets were included only if the absolute mean adjusted expression was $>50$ in one or more groups, and differed by $10 \%$ or more from the mean for the pathogenfree group. Percentage change in the adjusted expression intensity (infection-induced change) for each probe set was calculated by subtracting the mean for the infected vehicle group from the mean for each treatment group, and then dividing the difference by the absolute mean for the infected vehicle group. Expression of condition A genes (Table 1) was greater in the infected vehicle group than in the pathogen-free group, and one or more treatments caused $50 \%$ or greater decrease relative to the infected vehicle group. Expression of condition $\mathrm{C}$ genes (Table 1) was less in the infected vehicle group than in the pathogen-free group, and one or more treatments caused a $50 \%$ or greater increase relative to the infected vehicle group. Probe sets were required to have a mean adjusted expression value of $>50$ for inclusion in condition $\mathrm{A}$ and less than -50 for inclusion in condition $\mathrm{C}$. Probe set lists were examined in IPA using the canonical pathway functionality. ${ }^{34}$ Observed $P$ values for all pathways were calculated by Fisher's exact test, followed by multiple test correction by the Benjamini-Hochberg procedure.

\section{Statistical Analysis}

Values are presented as means \pm SEM. The significance of differences between groups was assessed by analysis of variance, followed by Tukey's test for multiple comparisons, except as described for the comparison of IPA pathways. $P<0.05$ was considered significant.

\section{Results}

\section{Complementary Effects of Ang2 and TNF on Blood Vessel Enlargement}

The tracheal microvasculature of pathogen-free mice was segmentally organized in relation to the cartilage rings. Uniformly narrow capillaries spanned the mucosa over cartilage rings in a ladder-like manner (Figure 1A) and were connected to arterioles and venules located between cartilage rings. Seven days after infection with M. pulmonis, capillaries were enlarged to approximately twice the normal size and resembled venules (Figure 1B). Administration of the function-blocking Ang2 antibody throughout the infection significantly attenuated this remodeling, with mean vascular diameter decreasing by $24 \%$, from 21 to $16 \mu \mathrm{m}$ (Figure 1, C and F). The anti-TNF antibody also reduced the remodeling, decreasing mean vascular diameter by $38 \%$ (Figure 1, D and F). By comparison, this enlargement was entirely prevented when both antibodies were given together (Figure 1, E and F). Vessel diameters in these mice averaged $9 \mu \mathrm{m}$, which was the same as capillaries in pathogen-free mice (Figure 1F). Treatment with control $\mathrm{IgG}$ during the infection did not reduce the vascular enlargement (Supplemental Figure S1).

\section{Complementary Effects of Ang2 and TNF on Adhesion Molecule Expression}

In pathogen-free mice, expression of the adhesion molecules P-selectin, E-selectin, ICAM-1, and EphB4 is restricted to venules. ${ }^{4}$ Consistent with these earlier findings, P-selectin immunoreactivity was absent in capillaries of pathogen-free mice (Figure 1G) but was conspicuous in remodeled vessels after infection for 7 days (Figure 1H). This increase in P-selectin was completely prevented by blocking Ang2 and TNF together (Figure 1I). Similarly, expression of P-selectin, E-selectin, and ICAM-1, assessed by $48 \times 48$ Dynamic Array Chips, was significantly less in tracheas of infected mice treated with the antibody combination (Figure 1, J-L).

\section{Complementary Effects of Ang2 and TNF on Leakiness of Remodeled Vessels}

Tracheal blood vessels become leaky after $M$. pulmonis infection. ${ }^{4,710}$ Multiple methods, including high-resolution visualization of the endothelium, have shown that the leak results from the formation of intercellular gaps at cell junctions. ${ }^{10,39-41}$ By using fluorescent microspheres to quantify leakage, ${ }^{7,39}$ we found little leakage in tracheal blood vessels of pathogen-free mice (area density, $0.16 \%$ ), but found 10 -fold as much after infection (Figure 2, A, B, and F). Patches of extravasated microspheres were abundant in the wall of most remodeled blood vessels (Figure 2B). Inhibition of either Ang2 or TNF alone reduced the leakage by approximately half (Figure 2, C, D, and F), but inhibition of both Ang2 and TNF together reduced the leakage to the pathogen-free baseline (Figure 2, E and F). 
Complementary Effects of Ang2 and TNF on Pericyte Remodeling

Pericytes are important for maintaining the stability of blood vessels in the microcirculation. ${ }^{18,42-44}$ Loss of pericyte coverage is accompanied by vascular instability and leakiness. ${ }^{18,42,43}$ At 7 days after M. pulmonis infection, pericytes have more rounded cell bodies, shorter processes, and less vessel coverage. ${ }^{7}$ The shape change contributes more to the reduction in vessel coverage than loss of pericytes, because no evidence of pericyte apoptosis has been found. ${ }^{7}$ These changes are transient, and by 14 days, pericyte number and coverage are twice baseline. ${ }^{7}$ In pathogenfree mice, pericytes on tracheal capillaries were elongated,

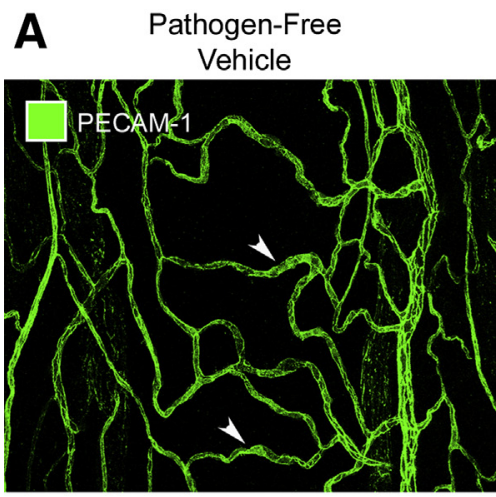

D M. pulmonis Infection

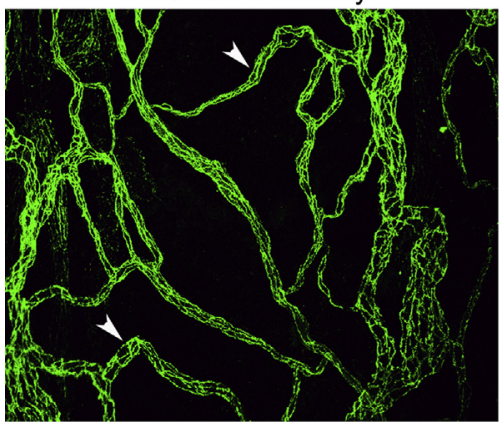

G
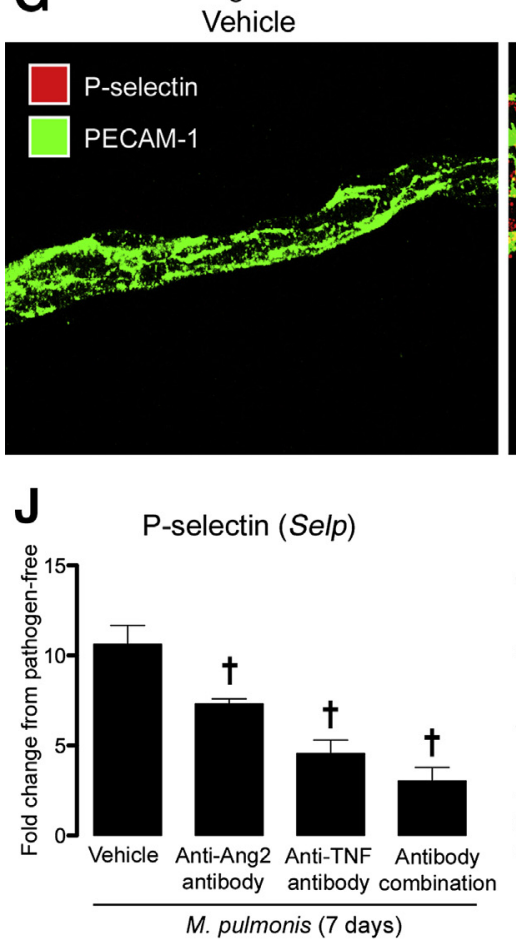

B M. pulmonis Infection

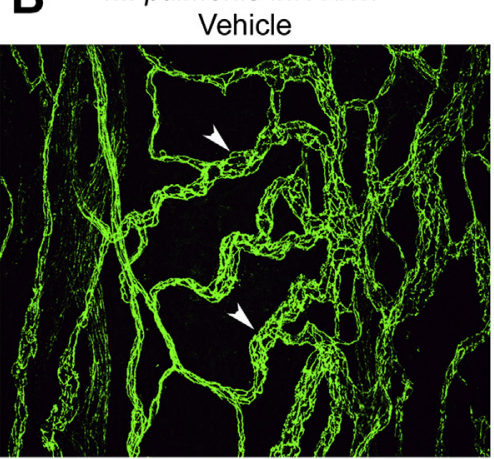

E M. pulmonis Infection Antibody Combination

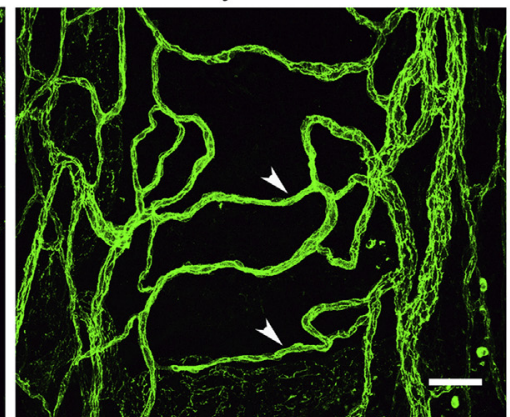

H M. pulmonis Infection Vehicle
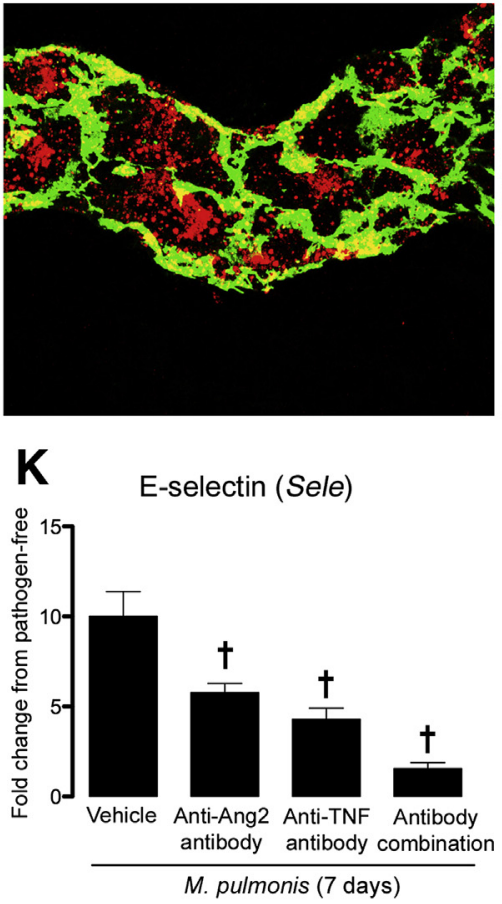

C M. pulmonis Infection

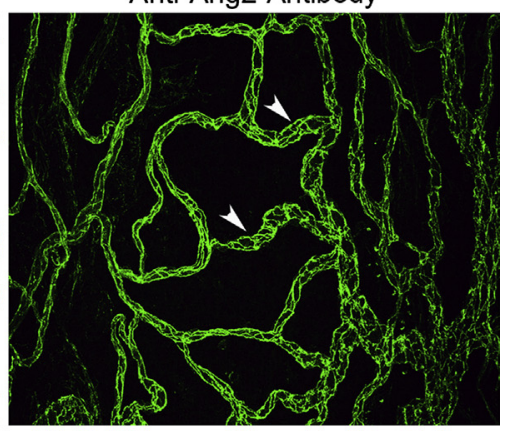

$\mathbf{F}$

Vessel Size

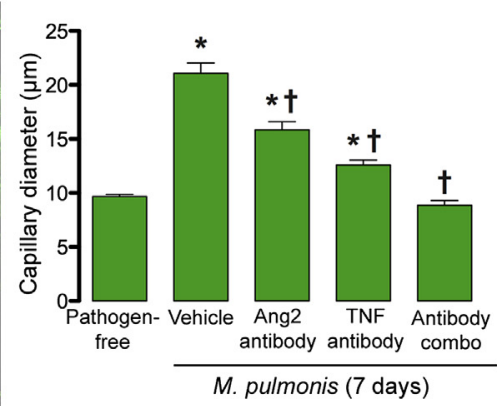

I M. pulmonis Infection Antibody combination
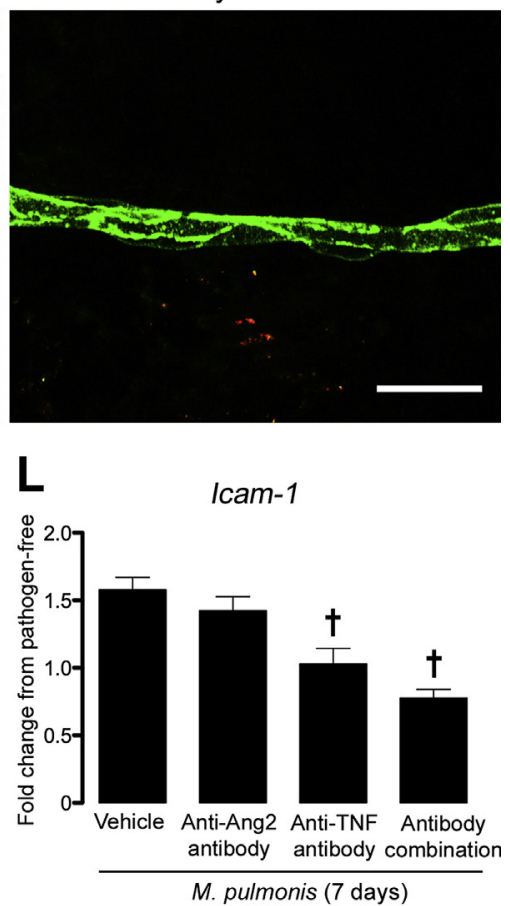
tightly associated with endothelial cells (Figure 2G), and had two or three thin processes aligned with the vessel direction (Figure 2G). Pericytes underwent conspicuous shape changes after infection (Figure 2H). Most had four to six short processes that extended from their rounded cell body and wrapped around the circumference of the remodeled vessels (Figure $2 \mathrm{H}$ ). Inhibition of Ang2 or TNF alone reduced the number of processes, but the shape and circumferential orientation remained approximately the same (Figure 2, I, J, and L). By comparison, when Ang2 and TNF were inhibited together, pericyte shape and vessel coverage were nearly normal (Figure 2, K and L).

\section{Complementary Effects of Ang2 and TNF on Lymphatic Sprouting}

Most lymphatics in the trachea of pathogen-free mice were located between cartilage rings and had few or no sprouts (Figure 3A). After infection for 7 days, the number of tapered, finger-like projections from the surface of lymphatics increased from 1 to 55 sprouts $/ \mathrm{mm}^{2}$ (Figure 3, B and F). When either Ang2 or TNF was inhibited during the infection, the number of lymphatic sprouts was reduced by $40 \%$ or $70 \%$, respectively (Figure 3, C, D, and F). When Ang2 and TNF were inhibited together, the number of lymphatic sprouts was reduced almost to 0 , as found in pathogen-free mice (Figure 3, E and F).

\section{Complementary Effects of Ang2 and TNF on Neutrophil Influx and Cytokine Expression}

Neutrophils are the most abundant leukocytes recruited into the airways and lung during the first week of M. pulmonis infection, with significant influx being evident at 3 days. ${ }^{45}$ Neutrophils are known to contribute to vascular remodeling after infection, because vessel changes do not occur if neutrophil influx is blocked. ${ }^{45}$ To determine whether inhibition of Ang2 and/or TNF reduced the influx of neutrophils, we quantified cells in the tracheal mucosa stained for the neutrophil marker S100a9 at 7 days after infection. ${ }^{45}$ Neutrophils were uncommon in the tracheal mucosa of pathogen-free mice (Figure $4 \mathrm{~A})^{8}$ but were abundant and widespread, but unevenly distributed, at 7 days after infection (Figure 4B). Neutrophil influx was slightly reduced when Ang2 was inhibited during the infection, but was reduced more when TNF was blocked (Figure 4, C, D, and F). Inhibition of Ang2 and TNF together was accompanied by an even larger reduction in neutrophils (Figure 4, E and F), although the number was still greater than under pathogen-free conditions. Gene expression profiling by $48 \times 48$ Dynamic Array Chips revealed a 400 -fold increase in mRNA of the neutrophil marker S100a8 at 7 days after infection (Figure 4G). S100a8 and S100a9 colocalize with myeloperoxidase after $M$. pulmonis infection ${ }^{45}$ but are more sensitive markers of neutrophils for expression studies. Values for C-X-C chemokine ligand 1 (Cxcll) and IL-1 $\beta$ (Illb) increased 14- and 400-fold, respectively (Figure 4, H and I). Expression of these cytokines was significantly less in mice treated with the antibody combination (Figure 4, G-I).

\section{Synergistic Effects of Coinhibition of Ang2 and TNF on Inflammatory Gene Expression}

To build on findings that these adhesion molecules and cytokines were suppressed more by blocking Ang2 and TNF together than by inhibiting either one individually, we performed genome-wide expression analysis using Affymetrix GeneChip arrays on tracheas of mice, with the same experimental design as for the other studies (Table 1). Expression data were analyzed by two independent methods to validate the results, as detailed in Materials and Methods. For both, genes were selected for increases or decreases during infection coupled with treatment-induced suppression or augmentation of these changes. Method 1 selection criteria identified 7641 probe sets for annotated genes that changed $>25 \%$ during infection (4129 increased, 3512 decreased) (Table 1); 2576 of these changed $>50 \%$ with one or more treatments (1555 decreased, 1021 increased). Of the genes that changed $>50 \%$ with treatment, anti-Ang2 antibody affected $15 \%$ (392 genes), anti-TNF antibody affected $51 \%$ (1310 genes), and the antibody combination affected $72 \%$ (1866 genes) (Table 1). Effects of anti-Ang2 antibody on gene expression differed from the other treatments. Fewer genes were suppressed by the anti-Ang2 antibody, and those affected underwent smaller increases during infection (mean increase, $1.5 \pm 0.1$; maximum, sixfold) than

\footnotetext{
Figure 1 Effects of inhibition of angiopoietin-2 (Ang2) and/or tumor necrosis factor (TNF) on vascular remodeling during Mycoplasma pulmonis infection (7 days). A-E: Confocal microscopic images of blood vessels in tracheal whole mounts stained for platelet endothelial cell adhesion molecule 1 (PECAM-1; green) to compare the narrow capillaries (arrowheads) in a ladder-like pattern across a cartilage ring in a pathogen-free mouse (A) with the enlarged, remodeled vessels in the same location in an infected mouse treated with vehicle (B). The vascular enlargement is less when anti-Ang2 (C) or anti-TNF (D) antibody was given during the infection. $\mathbf{A}$ and $\mathbf{E}$ : Corresponding vessels in an infected mouse treated with the antibody combination are similar to those in the pathogen-free mouse. F: Tracheal vessels are twice as large in infected mice $(21 \pm 1 \mu \mathrm{m})$ as in pathogen-free mice $(10 \pm 0.2 \mu \mathrm{m})$, but are smaller after treatment with anti-Ang2 antibody $(16 \pm 1 \mu \mathrm{m})$ or anti-TNF antibody $(13 \pm 0.4 \mu \mathrm{m})$. However, vessel size in infected mice that received both antibodies $(9 \pm 0.4 \mu \mathrm{m})$ is the same as in pathogen-free controls. $\mathbf{G}$ and $\mathbf{H}$ : Images of vessels stained for P-selectin (red) and PECAM-1 (green) to compare the absence of P-selectin in a capillary over a cartilage ring of a pathogen-free mouse (G) with strong P-selectin staining in a remodeled vessel in the same location of an infected mouse (H). I: In contrast, P-selectin is absent in a corresponding vessel of an infected mouse treated with the antibody combination. J-L: Tracheal mRNA expression for P-selectin (J), E-selectin (K), and Icam1 (L), expressed as fold change from pathogen-free mice, is greatest in the infected vehicle group and least in the antibody combination group. Data are given as means \pm SEM ( $\mathbf{F}$ and $\mathbf{J}-\mathbf{L}$ ). $N=5$ mice per group (F); $N=4$ to 5 mice per group (J-L). ${ }^{\star} P<0.05$ versus pathogen-free group; ${ }^{\dagger} P<0.05$ versus infected vehicle group treated with phosphate-buffered saline vehicle. Scale bars: $50 \mu \mathrm{m}$ (E, applies to A-E); $20 \mu \mathrm{m}$ (I, applies to $\mathbf{G}-\mathbf{I})$.
} 
with the anti-TNF antibody (mean increase, $4.2 \pm 0.7$; maximum, 324-fold) or antibody combination (mean increase, $5.3 \pm 0.7$; maximum, 324-fold) (Tables 1 and 2).

Genes suppressed by treatment (condition A) included a large cohort of inflammatory cytokines and chemokines, markers of activated neutrophils, lymphocytes, and macrophages, and other indices of inflammation (Table 3). The antibody combination resulted in uniformly greater suppression of these genes than either antibody given individually. The antibody combination not only suppressed most of the genes affected by anti-Ang 2 or anti-TNF antibody alone, but also reduced expression of many genes that had the largest increases
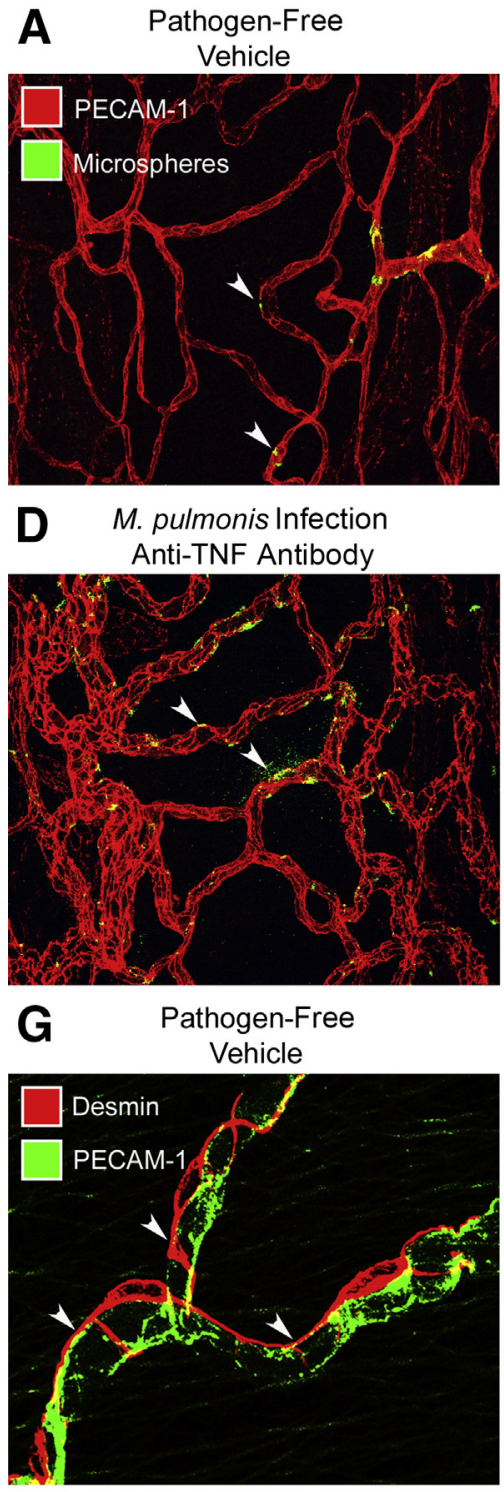

J M. pulmonis Infection

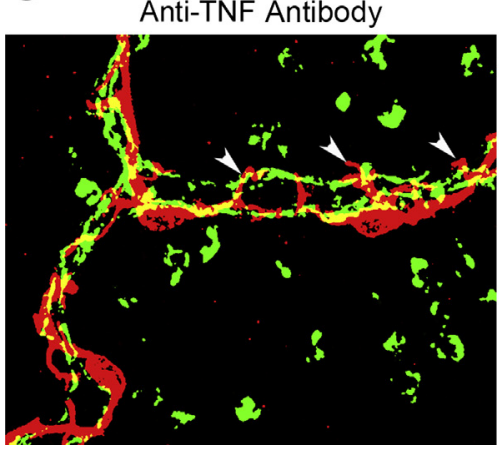

B M. pulmonis Infection

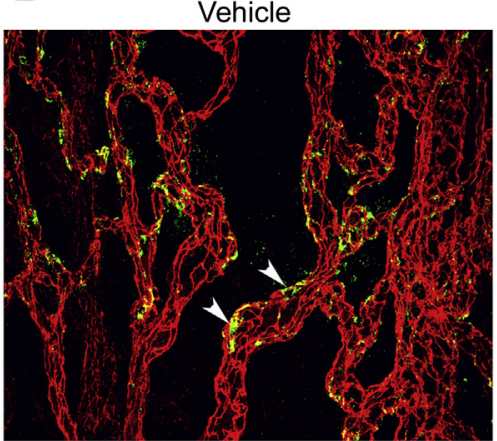

E M. pulmonis Infection

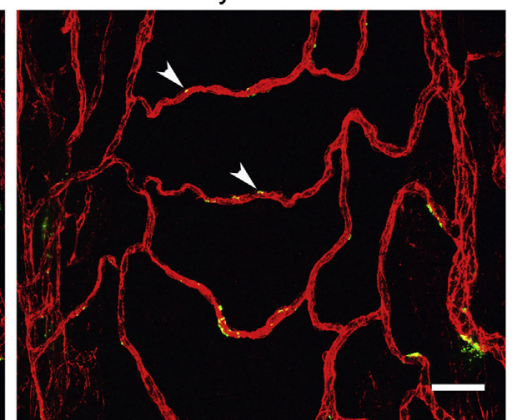

H M. pulmonis Infection

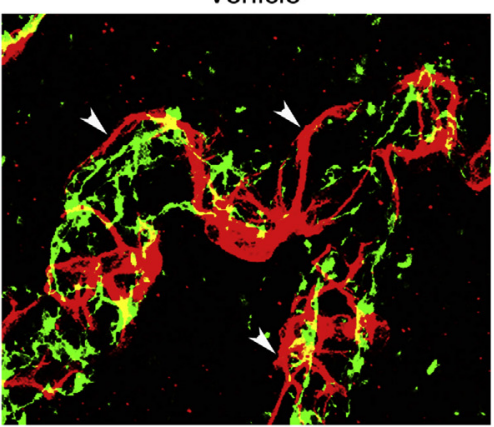

K M. pulmonis Infection Antibody Combination

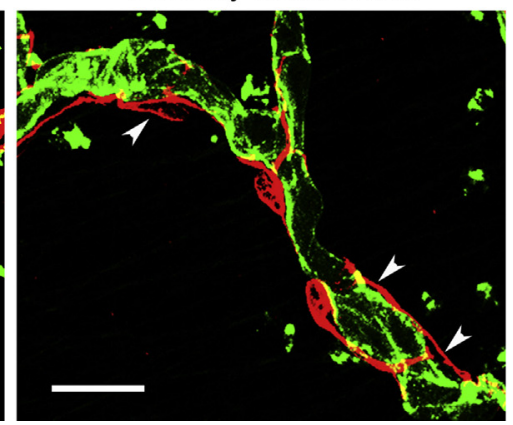

C M. pulmonis Infection

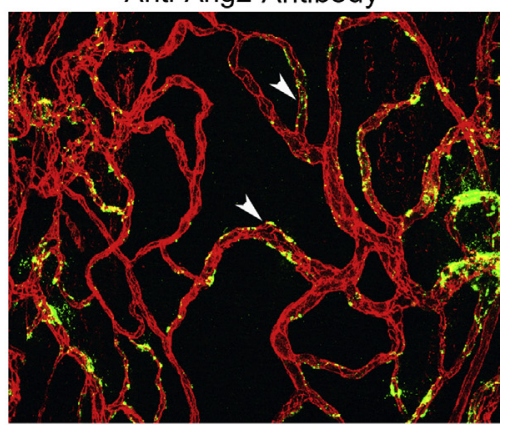

$\mathbf{F}$

Microsphere Leakage

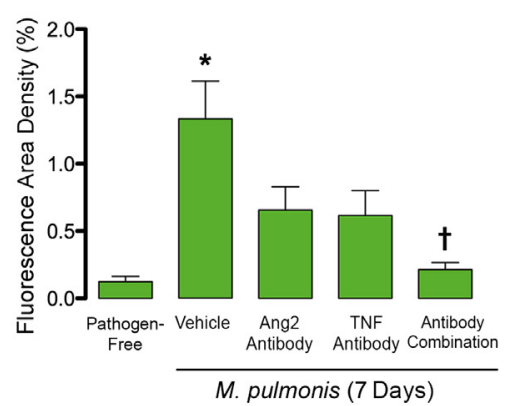

M. pulmonis Infection Anti-Ang2 Antibody

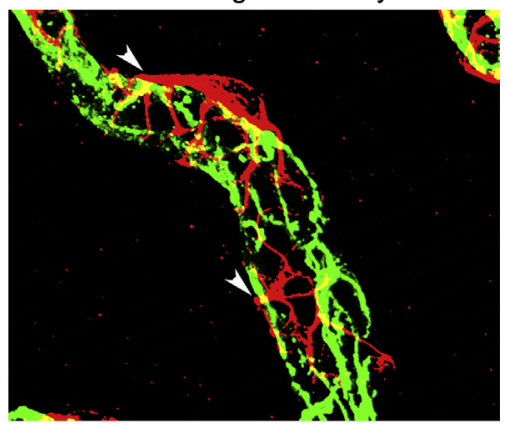

L

L Pericyte Remodeling

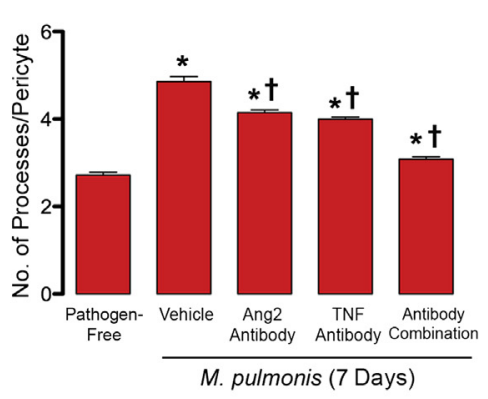


during infection, including S100a8, Cxcl1, Cxcl2, Cxcl3, Cd274 (PD-L1), IL-1 $\beta$, matrix metallopeptidase 3, Pselectin, and Tnfaip3 (A20) (Table 3). In addition to those in Table 3, genes indicative of inflammatory and immune responses that were up-regulated by infection and suppressed $>50 \%$ by the antibody combination included $C d 244$ (2B4), Cd80 (B7-1), E-selectin, Icam1, Illa, il8rb (Cxcr2), Il17a, Nfkb1, Nfkbia, Nfkbib, Tnfsf10 (TNF-related apoptosis-inducing ligand treatment), and Tnfrsfl1 $1 b$ (osteoprotegerin).

Support for synergistic effects of the antibody combination came from an analysis of the 100 genes that had the greatest increases in expression during infection (Figure 5). These included all genes in Table 3. Suppression of infection-induced changes in these genes was consistently greater with the antibody combination $(-73 \%)$ than with anti-Ang2 $(2 \%)$ or antiTNF (-49\%) antibody alone (Figure 5A). Similar differences were found for all 1006 condition A genes (Figure 5A). Consistent with this synergistic effect, suppression by the antibody combination exceeded the sum of the corresponding amounts of suppression by the individual antibodies (Figure 5B). The synergistic effect averaged $57 \%$ for the top 100 genes and 21\% for all 1006 genes (Figure 5B). Synergy was less for genes with smaller infection-induced changes because of greater suppression by the anti-Ang2 antibody (Figure 5A).

Many of the 3512 genes that decreased in expression during infection were affected by one or more treatments (Table 1). However, unlike the inflammatory attributes of most condition A genes, many genes in condition $\mathrm{C}$ were associated with metabolism, energy production, cell cycle activity, and other cellular processes (Supplemental Table S1). Still, the antibody combination had a larger effect on suppressing the changes than the individual antibodies (Supplemental Table S1).

To determine the effect of treatment on genes associated with endothelial cells and pericytes, we examined a collection of 35 genes involved in growth and remodeling of blood vessels and lymphatic vessels (Supplemental Table S2). Only four of these genes (Lyve1, Pecaml, Tnf, Tnfrsflb) met the selection criteria, largely because of the small expression changes during infection. Although many were affected by treatment (Supplemental Table S2), detection of gene expression changes in the relatively small population of endothelial cells and pericytes in the trachea could have been limited by assaying the entire organ.

The functional consequences of the observed alterations in gene expression were analyzed by IPA tools to compare the effects of the treatments on canonical pathways activated by infection. Many genes that increased in expression during infection (condition A, selection method 2) were associated with activation of pathways involved in leukocyte adhesion and migration, $\mathrm{T}$ - and $\mathrm{B}$-lymphocyte signaling, macrophage activation, dendritic cell maturation, IL-6, IL-8, IL-10, and IL-17 activity, and NF- $\kappa \mathrm{B}$, mitogen-activated protein kinase, and peroxisome proliferator-activated receptor signaling (Table 4). Consistent with the extensive neutrophil influx, granulocyte adhesion and diapedesis were the most highly activated pathways revealed by IPA (Table 4). All of these pathways were suppressed by one or more treatments, and the antibody combination caused the greatest suppression of most pathways (Table 4). A heat map of these data highlighted the treatment-related differences in pathway activation (Figure 6).

Similarly, analysis by DAVID (condition A, selection method 1) revealed broad suppression by the antibody combination of pathways associated with inflammatory responses, leukocyte chemotaxis, cytokine and chemokine signaling, and defense responses to bacterial infection. The anti-TNF antibody alone suppressed many of the pathways to a lesser extent, but the anti-Ang2 antibody did not. The inflammatory emphasis of pathways identified by IPA as activated by infection and suppressed by treatment (Table 4) contrasted with those where treatment had no significant effect (Supplemental Table S3). Pathways that were not significantly affected by any treatment are examples of processes that changed during infection but had no apparent involvement of Ang2 and TNF.

Consistent with the types of genes identified by condition C criteria (Supplemental Table S1), analysis by IPA revealed significant changes in metabolic pathways involved in mitochondrial function, oxidative phosphorylation, calcium signaling, and gluconeogenesis (Supplemental Table S4).

\footnotetext{
Figure 2 Effects of inhibition of angiopoietin-2 (Ang2) and/or tumor necrosis factor (TNF) on vascular leakage and pericytes during Mycoplasma pulmonis infection (7 days). A-E: Confocal microscopic images comparing the extravasation of green fluorescent 50-nm microspheres (arrowheads) from blood vessels [red, platelet endothelial cell adhesion molecule 1 (PECAM-1)] in tracheal whole mounts from a pathogen-free mouse (A), an infected mouse (B), and infected mice treated with anti-Ang2 antibody (C), anti-TNF antibody (D), or the antibody combination (E). F: Consistent with these images, measurements of extravasated microspheres in the tracheal mucosa over cartilage rings show 10 -fold greater leakage in infected mice $(1.75 \% \pm 0.33 \%)$ than in pathogen-free mice $(0.16 \% \pm 0.05 \%)$ and show $>60 \%$ reduction after treatment with the anti-Ang2 antibody $(0.66 \% \pm 0.17 \%)$ or anti-TNF antibody $(0.62 \% \pm 0.19 \%)$. Even more striking is that the extravasation was near the baseline level in mice treated with both antibodies $(0.21 \% \pm 0.05 \%)$ during the infection. G-K: Confocal microscopic images of pericytes (red, desmin, arrowheads) on blood vessels (green, PECAM-1) in tracheal whole mounts. Pericytes have two or three elongated processes on capillaries in a pathogen-free mouse $(\mathbf{G})$ but are more irregularly shaped and have abundant short processes extending from rounded cell bodies on remodeled vessels after infection $(\mathbf{H})$. Pericyte shape is more regular after treatment with anti-Ang2 (I) or anti-TNF (J) antibody and almost normal in mice treated with both antibodies (K). L: The number of processes per pericyte was relatively small in pathogen-free mice $(2.72 \pm 0.07)$ and is larger after infection $(4.86 \pm 0.11)$, but the number decreases after treatment with anti-Ang2 antibody $(4.15 \pm 0.06)$ or anti-TNF antibody $(4.00 \pm 0.05)$ and is approximately normal with both antibodies $(3.08 \pm 0.05)$. Data are given as means \pm SEM $(\mathbf{F}$ and $\mathbf{L}) . N=9$ to 11 mice per group $(\mathbf{F}) ; N=5$ mice per group $(\mathbf{L})$. ${ }^{*} P<0.05$ versus pathogen-free group; ${ }^{\dagger} P<0.05$ versus infected vehicle group treated with phosphate-buffered saline vehicle. Scale bars: $50 \mu \mathrm{m}(\mathbf{E}$, applies to $\mathbf{A}-\mathbf{E}) ; 20$ $\mu \mathrm{m}$ (K, applies to $\mathbf{G}-\mathbf{K}$ ).
} 

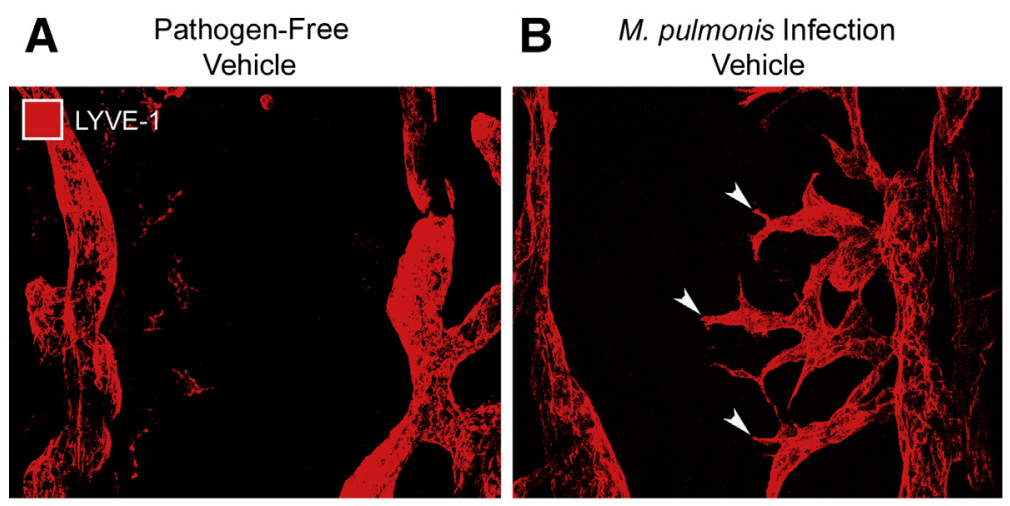

\section{M. pulmonis Infection}
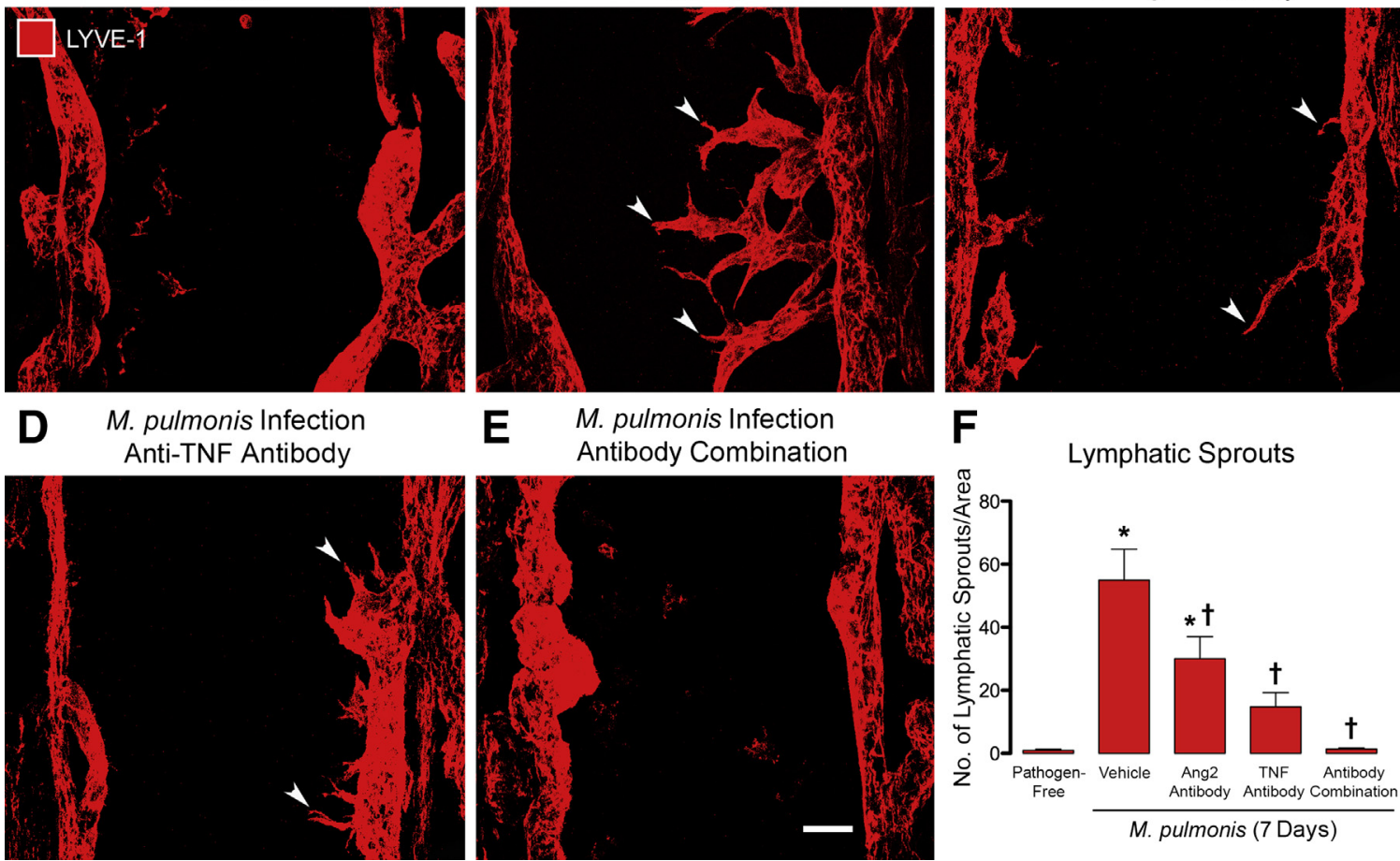

\section{E M. pulmonis Infection}

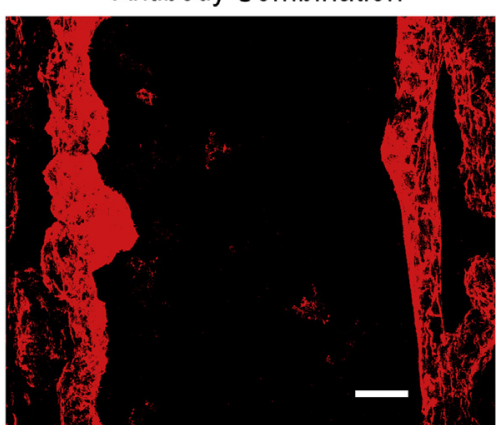

$\mathbf{F}$

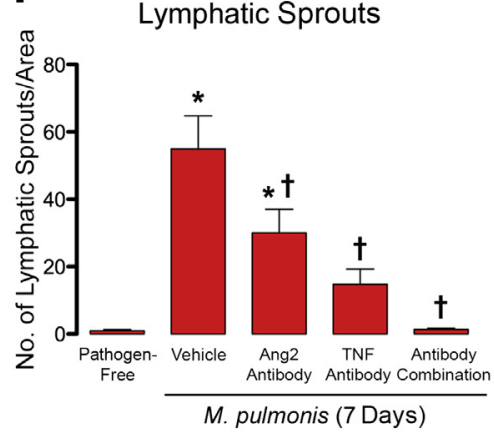

Figure 3 Effects of inhibition of angiopoietin-2 (Ang2) and/or tumor necrosis factor (TNF) on lymphatic sprouting during Mycoplasma pulmonis infection (7 days). A-E: Confocal microscopic images of lymphatic vessels [red, lymphatic vessel endothelial hyaluronan receptor (LYVE-1)] in the mucosa over cartilage rings of tracheal whole mounts. Lymphatic sprouts are absent in the pathogen-free mouse (A) but appear as abundant tapered, finger-like sprouts (arrowheads) after infection (B). Lymphatic sprouts are less numerous after treatment with anti-Ang2 antibody (C) or anti-TNF antibody (D) and absent after treatment with both antibodies (E). F: Lymphatic sprouts, expressed per $\mathrm{mm}^{2}$ of mucosa, are rare in pathogen-free mice $\left(1 \pm 0.3\right.$ per $\left.\mathrm{mm}^{2}\right)$ but are 50 times as abundant after infection for 7 days $\left(55 \pm 10\right.$ per $\left.\mathrm{mm}^{2}\right)$. Lymphatic sprouts reduce by treatment with anti-Ang2 antibody $\left(30 \pm 7\right.$ per mm $\left.{ }^{2}\right)$ or anti-TNF antibody $\left(15 \pm 5\right.$ per $\left.\mathrm{mm}^{2}\right)$ and are nearly absent with both antibodies $\left(1.3 \pm 0.4\right.$ per $\left.\mathrm{mm}^{2}\right)$. Data are given as means \pm SEM $(\mathbf{F})$. $N=7$ to 10 mice per group (F). ${ }^{\star} P<0.05$ versus pathogen-free group; ${ }^{\dagger} P<0.05$ versus infected vehicle group treated with phosphate-buffered saline vehicle. Scale bar $=50 \mu \mathrm{m}$ (E, applies to $\mathbf{A}-\mathbf{E})$.

\section{Discussion}

The present study sought to determine whether Ang2 and TNF have cooperative effects on the initial phase of vascular remodeling and lymphatic sprouting during the development of airway inflammation after M. pulmonis infection. Our study focused on the first week after infection when airway blood vessels and lymphatics change most rapidly. ${ }^{4,5}$ Prior work revealed that inhibition of either Ang2 or TNF can reduce, but not prevent, vascular remodeling and lymphatic sprouting during this period. ${ }^{5,20}$ Therefore, we designed experiments to determine whether Ang2 and TNF acting together were responsible for the initial phase of vascular remodeling. Our approach was to block the action of Ang2 (antibody 3.19.3, AZD5180 ${ }^{36}$ ) and TNF (antibody MP6-XT22 $2^{37,38}$ ) alone or together during the infection. This was the first use of these antibodies together in this setting. Consistent with previous reports, ${ }^{5,20}$ we found that inhibition of either Ang2 or TNF alone reduced vascular remodeling, leakage, and lymphatic sprouting at 7 days of infection. More important, our findings also revealed that concurrent inhibition of Ang2 and TNF completely prevented multiple indices of vascular remodeling and lymphatic sprouting. Genome-wide array studies of gene expression provided further evidence of synergistic effects of blocking Ang2 and TNF together. The antibody combination suppressed the expression of a broad range of genes encoding inflammatory cytokines, adhesion molecules, and other proteins activated during infection, and the amount of suppression was significantly greater than the reduction caused by either antibody given alone. These observations implicate Ang2 and TNF as essential factors that act synergistically in the initial phase of vascular remodeling after infection (Figure 7).

\section{Suppression of Remodeling of Blood Vessels by Inhibition of Ang2 and TNF Together}

TNF contributes to the initiation of vascular remodeling after M. pulmonis infection but is not the sole driver. Measurements by quantitative RT-PCR show rapidly increased and sustained TNF expression after infection. ${ }^{8,20,45}$ Vascular remodeling is reduced, but not prevented, by TNF blockade or deletion of TNF- $\alpha$ receptors (Tnfr1, Tnfrsf1a). ${ }^{20}$ TNF is apparently not 

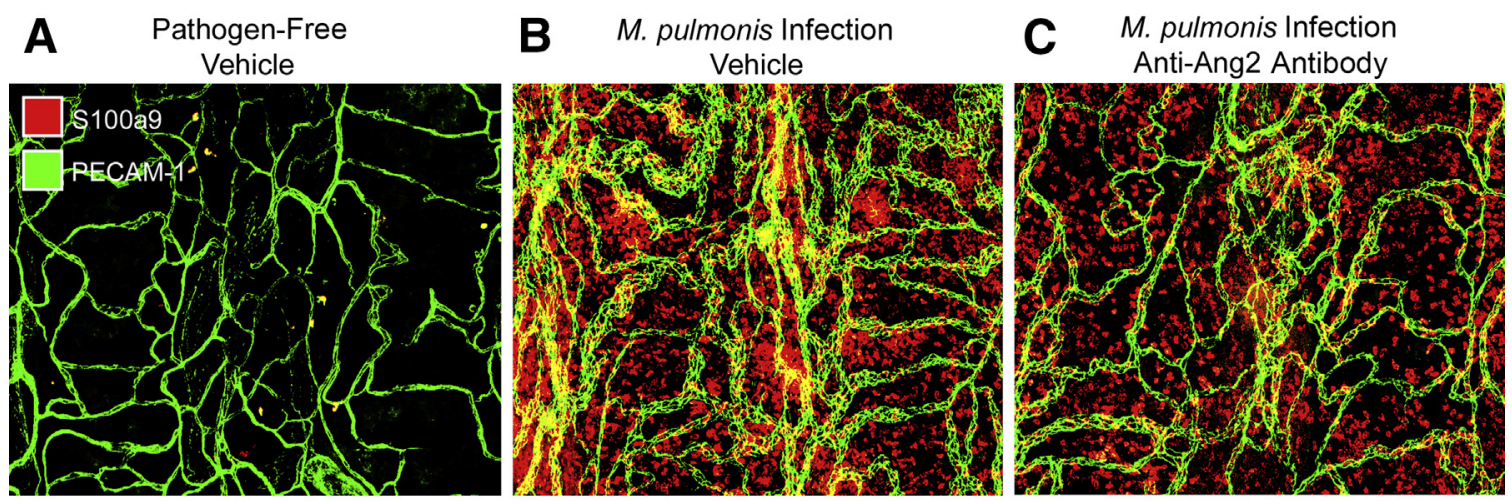
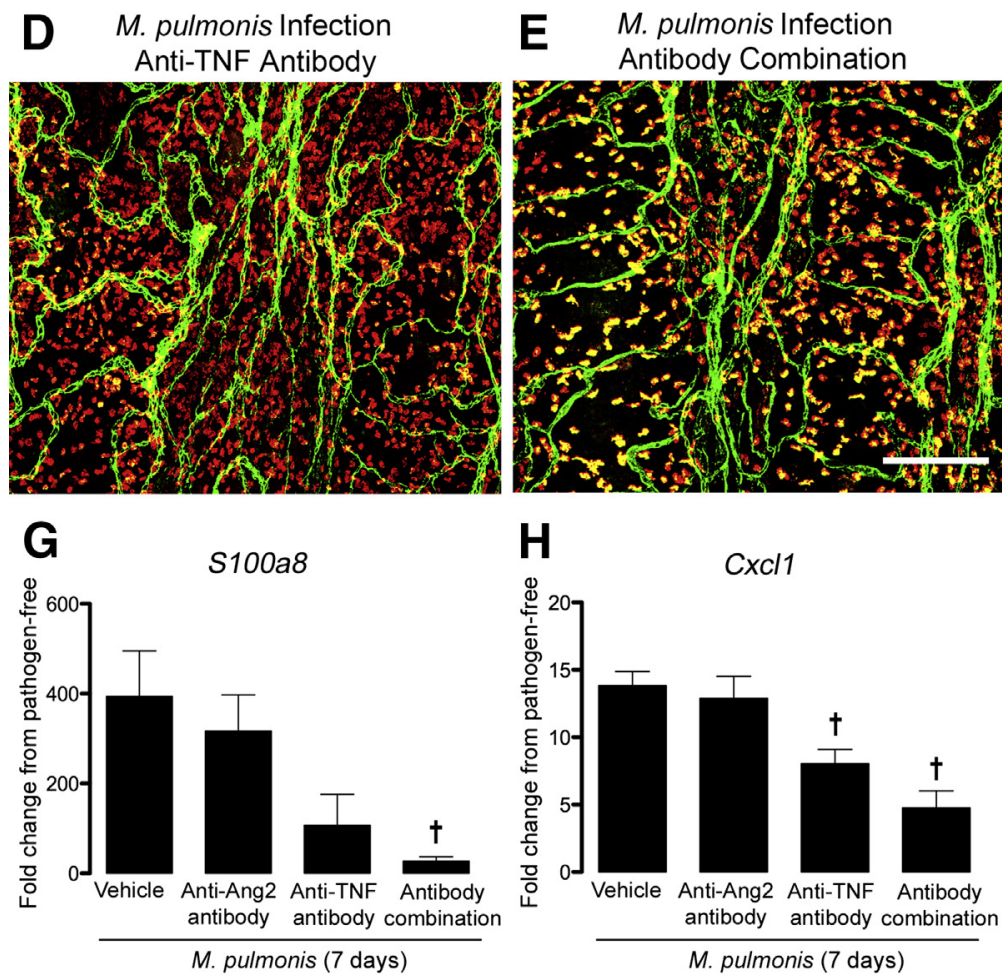
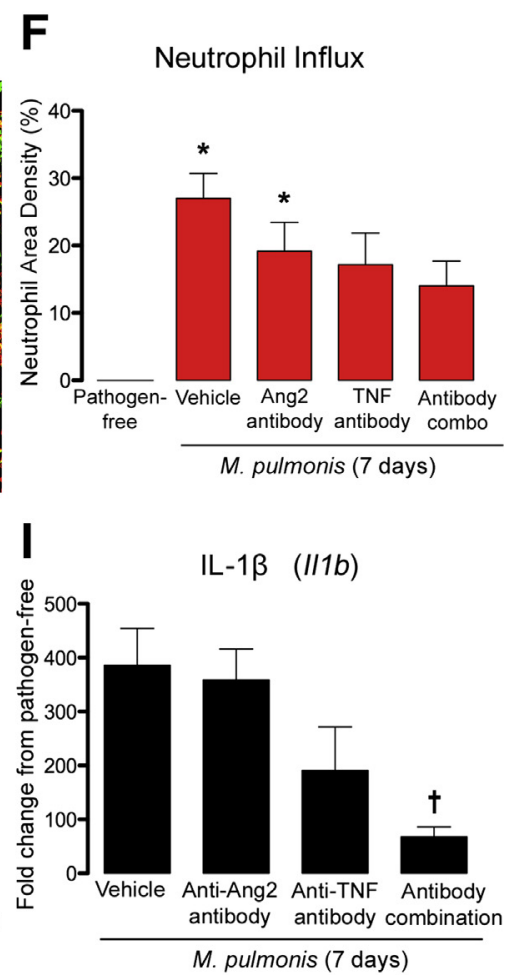

Figure 4 Effects of inhibition of angiopoietin-2 (Ang2) and/or tumor necrosis factor (TNF) on neutrophil influx and inflammatory cytokines. A-E: Confocal microscopic images of neutrophils (red, S100a9) and blood vessels [green, platelet endothelial cell adhesion molecule 1 (PECAM-1)] in tracheal whole mounts. Neutrophils are sparse in the pathogen-free trachea (A) but are abundant after Mycoplasma pulmonis infection for 7 days (B). Neutrophils are less numerous in mice treated with anti-Ang2 antibody (C) or anti-TNF antibody (D) and even less abundant in mice treated with both antibodies (E), but the number is still greater than in pathogen-free mice. F: Values for neutrophils stained for S100a9 were near 0 in the mucosa over cartilage rings in the pathogen-free group $(0.02 \% \pm 0.01 \%)$ but are numerous after infection $(27 \% \pm 4 \%)$. Neutrophil density reduces on treatment with anti-Ang2 antibody $(19 \% \pm 4 \%)$, anti-TNF antibody $(17 \% \pm 5 \%)$, or both antibodies $(14 \% \pm 4 \%)$, but is still greater than the pathogen-free baseline. G-I: Fold change in mRNA expression of S100a8 (G), Cxcl1 (H), and IL-1B (I) in the trachea of mice infected for 7 days with various concurrent treatments in relation to pathogen-free controls. Values for mice treated with anti-Ang2 antibody are approximately the same as the infected controls, but are significantly lower after treatment with anti-TNF antibody or both antibodies. Data are given as means \pm SEM (F-I). N $=4$ to 5 mice per group (F-I). ${ }^{*} P<0.05$ versus pathogen-free group (analysis of variance); ${ }^{\dagger} P<0.05$ versus infected group treated with phosphate-buffered saline vehicle. Scale bar $=200 \mu \mathrm{m}(\mathbf{E}$, applies to $\mathbf{A}-\mathbf{E})$.

sufficient to drive the change, because intratracheal administration of TNF does not induce vascular remodeling. ${ }^{45}$ The finding of little to no vascular remodeling in $\mathrm{Cxcr} 2$-null mice with M. pulmonis infection, despite increases in TNF mRNA and protein, ${ }^{45}$ is further evidence of the involvement of additional factors.

Ang2 destabilizes endothelial cells during vascular growth and remodeling through antagonism of Tie 2 receptors. ${ }^{4,12}$
Ang2 expression is up-regulated as the remodeling occurs, ${ }^{5,8}$ and inhibition of Ang2 reduces the remodeling. ${ }^{5}$ In addition to its direct effects, Ang2 amplifies the actions of TNF. Both have been implicated in vascular and lymphatic remodeling in inflammation and are known to have complementary actions. TNF-induced corneal angiogenesis is amplified by activation of Tie2 signaling, ${ }^{29}$ and administration of Ang2 with TNF results in greater lymphatic endothelial cell proliferation than 
Table 2 Treatment-Related Differences in Genes Suppressed during Infection

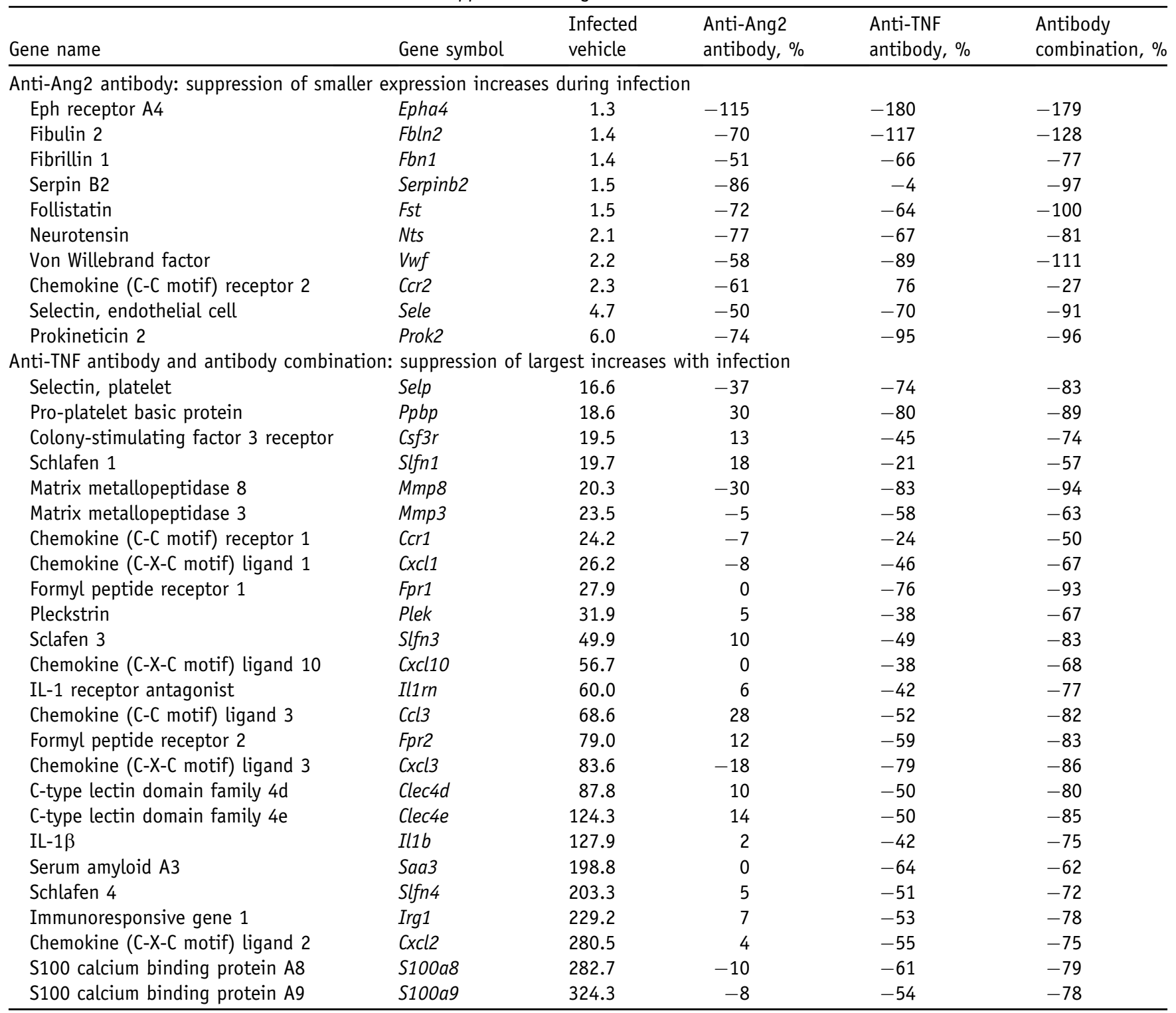

Genes with the largest increases during Mycoplasma pulmonis infection ( 7 days; condition A) ranked by fold increase from pathogen free. Genes included had at least one treatment reduce expression by $50 \%$ or more. Treatment with anti-Ang2 antibody alone suppressed genes that underwent more modest increases after infection than with anti-TNF antibody or antibody combination. More negative values indicate greater suppression of the infection-induced increase in expression. A value of $-100 \%$ indicates complete suppression of the increase, and values $<-100 \%$ indicate suppression of expression to lower than the pathogen-free level.

Ang2, angiopoietin-2; TNF, tumor necrosis factor.

administration of TNF alone. ${ }^{16}$ TNF induces leukocyte rolling, but not adhesion, in Ang2-null mice, consistent with Ang2 modulation of endothelial cell sensitivity to TNF, possibly through the up-regulation of cell adhesion molecules. ${ }^{16,28}$ Of relevance to the present studies, loss-of-function experiments have shown that inhibition of Ang2 reduces TNF mRNA expression by a third in mice infected with M. pulmonis for 7 days. ${ }^{5}$ In gain-of-function experiments, TNF up-regulates Ang2 mRNA expression and immunoreactivity. ${ }^{16,27}$ Inhibition of Ang2 or TNF alone reduced, but did not prevent, vascular remodeling in our experiments, but inhibition of the two together completely blocked vascular enlargement, leakiness, and P-selectin up-regulation.

\section{Suppression of Remodeling of Pericytes by Inhibition of Ang2 and TNF Together}

The elongated cell bodies and long processes of pericytes changed after $M$. pulmonis infection. The cell body was more rounded, and processes were shorter and provided less vessel coverage. The absence of pericyte apoptosis after infection raises the possibility that shape changes contribute 
Table 3 Gene Expression Increased by Infection and Suppressed by Treatment

\begin{tabular}{|c|c|c|c|c|c|}
\hline Gene name & Gene symbol & $\begin{array}{l}\text { Infected } \\
\text { vehicle }\end{array}$ & $\begin{array}{l}\text { Anti-Ang2 } \\
\text { antibody, \% }\end{array}$ & $\begin{array}{l}\text { Anti-TNF } \\
\text { antibody, \% }\end{array}$ & $\begin{array}{l}\text { Antibody } \\
\text { combination, \% }\end{array}$ \\
\hline S100 calcium binding protein A9 & S100a9 & 324 & -8 & -54 & -78 \\
\hline S100 calcium binding protein $\mathrm{A} 8$ & S100a8 & 283 & -10 & -61 & -79 \\
\hline Chemokine ( $\mathrm{C}-\mathrm{X}-\mathrm{C}$ motif) ligand 2 & Cxcl2 & 281 & 4 & -55 & -75 \\
\hline Immunoresponsive gene 1 & $\operatorname{Irg} 1$ & 229 & 7 & -53 & -78 \\
\hline Schlafen 4 & Slfn4 & 203 & 5 & -51 & -72 \\
\hline C-type lectin domain family $4 \mathrm{e}$ & Clec4e & 124 & 14 & -50 & -85 \\
\hline C-type lectin domain family $4 \mathrm{~d}$ & Clec4d & 88 & 10 & -50 & -80 \\
\hline Chemokine ( $\mathrm{C}-\mathrm{X}-\mathrm{C}$ motif) ligand 3 & $\mathrm{Cxcl3}$ & 84 & -18 & -79 & -86 \\
\hline Formyl peptide receptor 2 & Fpr2 & 79 & 12 & -59 & -83 \\
\hline Chemokine ( $\mathrm{C}-\mathrm{C}$ motif) ligand 3 & $\mathrm{Ccl} 3$ & 69 & 28 & -52 & -82 \\
\hline Formyl peptide receptor 1 & Fpr1 & 28 & 0 & -76 & -93 \\
\hline Chemokine ( $\mathrm{C}-\mathrm{X}-\mathrm{C}$ motif) ligand 1 & Cxcl1 & 26 & -8 & -46 & -67 \\
\hline Chemokine ( $\mathrm{C}-\mathrm{C}$ motif) receptor 1 & Cor1 & 24 & -7 & -24 & -50 \\
\hline Matrix metallopeptidase 3 & Mmp3 & 23 & -5 & -58 & -63 \\
\hline Matrix metallopeptidase 8 & Mmp8 & 20 & -30 & -83 & -94 \\
\hline Schlafen 1 & Slfn1 & 20 & 18 & -21 & -57 \\
\hline Colony-stimulating factor 3 receptor & Csf3r & 19 & 13 & -45 & -74 \\
\hline Pro-platelet basic protein & Ppbp & 19 & 30 & -80 & -89 \\
\hline Selectin, platelet & Selp & 17 & -37 & -74 & -83 \\
\hline Lymphocyte antigen 6 , locus I & Ly6i & 16 & 11 & -51 & -58 \\
\hline Chemokine ( $\mathrm{C}-\mathrm{C}$ motif) ligand 4 & $\mathrm{Ccl} 4$ & 15 & 2 & -52 & -76 \\
\hline
\end{tabular}

The infected vehicle column lists fold increases in expression of 35 of the 100 genes that had the greatest increases after infection: at least $25 \%$ increase at 7 days after Mycoplasma pulmonis infection, relative to the pathogen-free value scaled to 1.0 , and $50 \%$ or more suppression of this increase by one or more treatments. Three treatment columns list percentage change in gene expression, where more negative values indicate greater suppression of the infectioninduced increase. A value of $-100 \%$ indicates complete suppression to the pathogen-free level. Antibody combination had greater effect than other treatments on 34 of these genes, and for 30 genes, this effect exceeded the sum of effects of the two antibodies given individually (synergy). See heat map in Figure 6.

Ang2, angiopoietin-2; TNF, tumor necrosis factor.

more to the reduction of vessel coverage than reduction in pericyte number. ${ }^{7}$ Nonetheless, these changes are transient, and pericyte number and coverage double by 14 days after infection. ${ }^{7}$ Ang2 weakens pericyte-endothelial interactions and leads to pericyte loss and endothelial cell activation in models of inflammation. ${ }^{12,18,48}$ TNF can stimulate pericyte remodeling, proliferation, and migration through $\alpha 2$ integrin switching. ${ }^{21}$ In our study, coinhibition of Ang2 and TNF completely prevented the pericyte shape changes and reduction in vessel coverage. Because the inhibitory antibodies were started 1 day before $M$. pulmonis infection, the observed changes reflected suppression, rather than reversal, of pericyte remodeling. The contribution of pericyte proliferation to the changes after infection could be elucidated by lineage tracing experiments. ${ }^{49}$

\section{Suppression of Remodeling of Lymphatics by Inhibition of Ang2 and TNF Together}

In the present study, lymphatic sprouting was reduced by inhibition of Ang2 or TNF alone, but was completely blocked by the antibody combination. Previous studies have shown that lymphangiogenesis is reduced when TNF signaling is blocked pharmacologically or by gene 
A

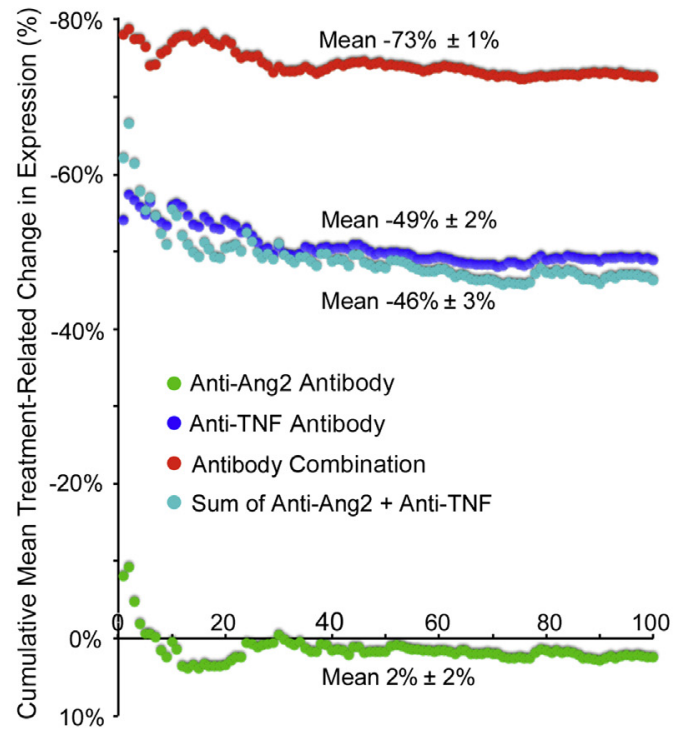

All 1006 Condition A Genes

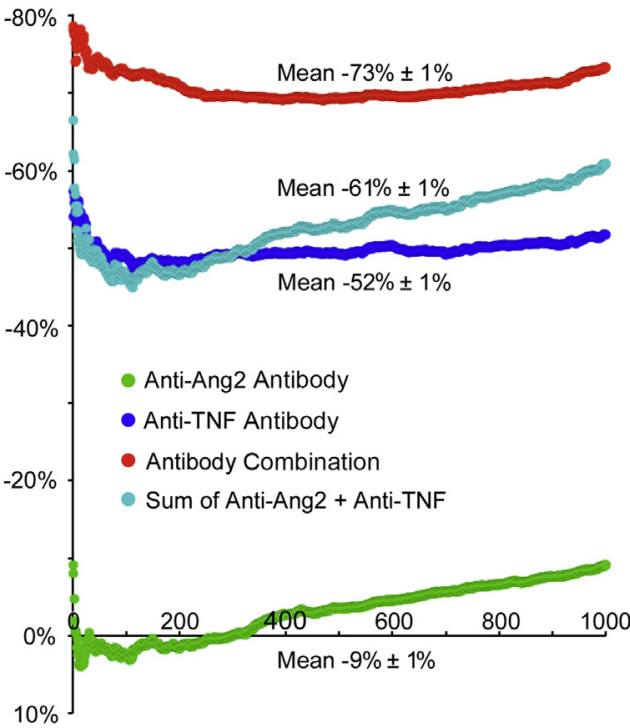

Suppression of Genes Ranked from Largest to Smallest Increase during Infection

B

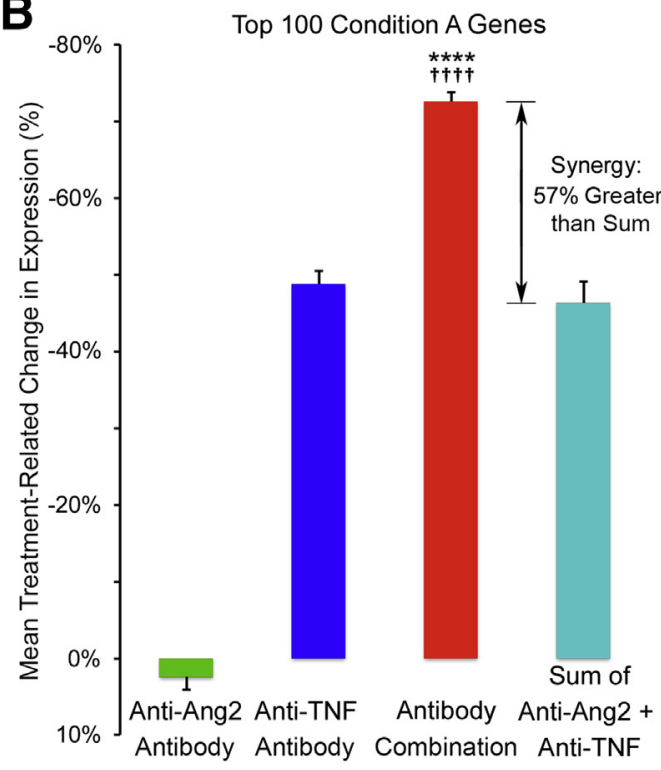

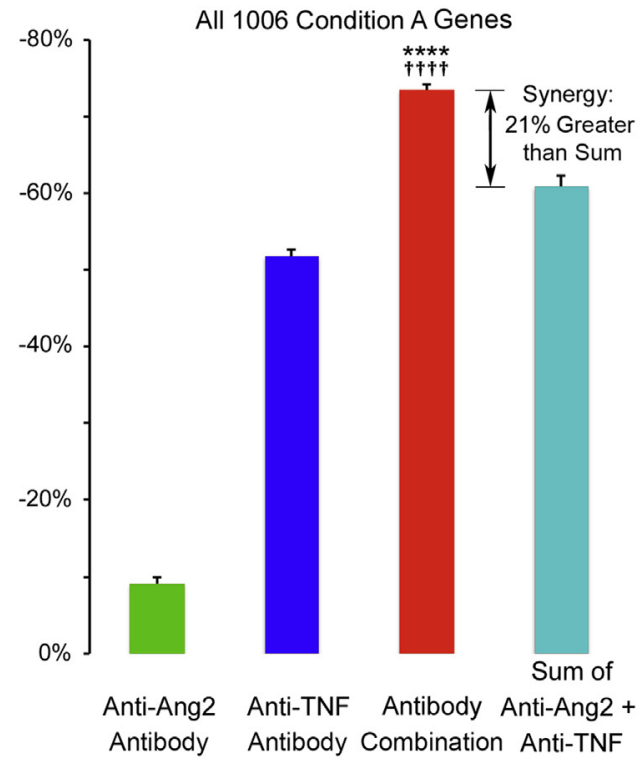

Suppression of Genes with Increased Expression during Infection

Figure 5 Treatment-related differences in suppression of infection-induced gene expression. A: Plots comparing cumulative moving average changes in gene expression after Mycoplasma pulmonis infection (7 days) during treatment with vehicle, anti-angiopoietin-2 (Ang2) antibody, anti-tumor necrosis factor (TNF) antibody, or the antibody combination. Genes, ranked left to right from largest to smallest, increase after infection, have a $25 \%$ or greater increase in expression during infection, and have at least $50 \%$ suppression by one or more treatments (condition A; Table 1). Plots compare values for 100 genes (left panel) that have the greatest increases with infection and all 1006 condition A genes (right panel). Suppression by the antibody combination (red) is greater than that for anti-TNF alone (blue) or anti-Ang2 alone (green) and is also greater than the sum of values for the individual antibodies (cyan). B: Bar graphs compare the overall means for the treatment groups, both for the 100 top genes (left panel) and all 1006 genes (right panel) shown in A. Compared with the sum of the individual agents, the mean for the antibody combination is $57 \%$ greater (synergy) for the top 100 genes and $21 \%$ greater for all 1006 genes. $* * * * P<0.0001$ for the antibody combination versus anti-Ang2 or anti-TNF given alone; ${ }^{\dagger+\dagger} P<0.0001$ versus the sum of the values for the individual agents, determined by analysis of variance and Tukey's multiple comparisons test.

silencing. ${ }^{20}$ Ang2 is required for the maturation of primitive lymphatics into networks of initial and collecting vessels $^{13-15}$ and can act as a lymphangiogenic factor. ${ }^{3,15-17}$ Genetic deletion of Ang2 reduces lymphangiogenesis in experimental colitis, where the adverse effects are interpreted as partially because of the loss of Ang2-driven lymphangiogenesis. ${ }^{3}$ Ang2-blocking antibodies also reduce lymphangiogenesis in tumors. ${ }^{17}$ 
Table 4 IPA Analysis of Pathways

\begin{tabular}{|c|c|c|c|c|c|}
\hline $\begin{array}{l}\text { Functional grouping of canonical pathways } \\
\text { assessed by IPA }\end{array}$ & $\begin{array}{l}\text { Infected } \\
\text { vehicle }\end{array}$ & $\begin{array}{l}\text { Anti-Ang2 } \\
\text { antibody }\end{array}$ & $\begin{array}{l}\text { Anti-TNF } \\
\text { antibody }\end{array}$ & $\begin{array}{l}\text { Antibody } \\
\text { combination }\end{array}$ & $\begin{array}{l}\text { Pathogen- } \\
\text { Free }\end{array}$ \\
\hline Granulocyte adhesion and diapedesis & -20.9 & -20.4 & -11.7 & 0.8 & 0 \\
\hline Other leukocyte adhesion and diapedesis & -14.3 & -13.8 & -8.4 & -2.7 & 0 \\
\hline Leukocyte extravasation signaling & -12.9 & -10.5 & -7.8 & -3.1 & 0 \\
\hline Macrophages in arthritis & -16.4 & -14.7 & -9.9 & -3.2 & 0 \\
\hline Macrophage $\mathrm{NO}$ and ROS & -13.9 & -12.3 & -9.6 & -2.5 & 0 \\
\hline $\mathrm{T}$ and $\mathrm{B}$ cells in arthritis & -7.6 & -7.3 & -6.5 & -4.0 & 0 \\
\hline B-cell activating factor signaling & -5.3 & -4.9 & -2.9 & -0.2 & 0 \\
\hline B-cell receptor signaling & -13.4 & -12.2 & -10.4 & -10.1 & 0 \\
\hline Acute phase response signaling & -14.8 & -13.5 & -10.2 & -4.8 & 0 \\
\hline TNFR1 signaling & -11.6 & -11.2 & -10.0 & -5.5 & 0 \\
\hline IL-10 signaling & -16.4 & -16.1 & -14.1 & -3.9 & 0 \\
\hline IL-17 signaling & -7.6 & -6.9 & -6.2 & -3.8 & 0 \\
\hline IL-17 signaling in airway cells & -10.4 & -10.1 & -8.4 & -6.3 & 0 \\
\hline IL-17 signaling in fibroblasts & -10.6 & -9.6 & -7.3 & -4.9 & 0 \\
\hline IL-17 signaling in arthritis & -8.0 & -8.0 & -6.6 & -2.4 & 0 \\
\hline fMLP signaling in neutrophils & -8.8 & -8.6 & -6.7 & -4.9 & 0 \\
\hline Toll-like receptor signaling & -11.1 & -10.8 & -8.1 & -1.1 & 0 \\
\hline iNOS signaling & -13.2 & -12.8 & -10.9 & -5.6 & 0 \\
\hline$N F-\kappa B$ signaling & -13.8 & -12.5 & -6.1 & -4.0 & 0 \\
\hline PPAR signaling & -9.6 & -9.1 & -3.9 & -0.6 & 0 \\
\hline p38 MAPK signaling & -6.7 & -6.3 & -4.8 & 0.0 & 0 \\
\hline
\end{tabular}

Pathways activated by infection and suppressed by treatment. The infected vehicle column lists $\log 10$ of $P$ values for pathways assessed by IPA for genes (condition A), where expression increased during Mycoplasma pulmonis infection for 7 days, relative to pathogen-free (scaled to 0 ), and the increase was suppressed by treatment. Three treatment columns show relative efficacy, calculated as $\log 10$ of $P$ values for infected vehicle group minus the log 10 of $P$ values for the corresponding treatment. Values closer to 0 reflect smaller differences from the pathogen-free baseline.

*For all but two of these pathways, the antibody combination reduced the activity closer to the baseline than the other treatments.

Ang2, angiopoietin-2; fMLP, N-formyl-Met-Leu-Phe; iNOS, inducible NO synthase; IPA, Ingenuity Pathway Analysis; LPS, lipopolysaccharide; MAPK, mitogenactivated protein kinase; N0, nitric oxide; PPAR, peroxisome proliferator-activated receptor; ROS, reactive oxygen species; TNF, tumor necrosis factor; TNFR, TNF receptor; TNFSF, TNF superfamily.

As far as we know, the present study is the first evidence of suppression of lymphatic sprouting in a model of airway inflammation by inhibition of Ang2 alone or together with TNF. The functional consequences of preventing lymphangiogenesis in the $M$. pulmonis model must still be determined. It is known, however, that new lymphatics that grow in this model are structurally abnormal and have impaired fluid and immune cell transport. ${ }^{6,8,9,50,51}$ Further studies are needed to learn whether inhibition of Ang2 and/or TNF under these conditions normalizes lymphatic function.

Effects of TNF on lymphatic vessels have not been studied as thoroughly as those on blood vessels. Because lymphatic endothelial cells have lower expression of TNF receptor 1 , the actions of TNF on lymphatics could be mediated through up-regulation of vascular endothelial growth factor-C (VEGF-C) in other cells. ${ }^{20,47}$ Previous work has identified macrophages as a source of VEGF-C at sites of inflammation. ${ }^{6,46,52}$ VEGF-C and VEGF-D, as ligands for VEGF receptors 2 and 3, are important drivers of lymphangiogenesis. ${ }^{53}$ TNF and IL-1 $\beta$ can up-regulate VEGF-C and VEGF-D expression through NF- $\kappa B$ signaling. ${ }^{47,52}$ TNF can promote lymphangiogenesis by recruiting and activating VEGF-C-producing immune cells. ${ }^{47,54}$ 


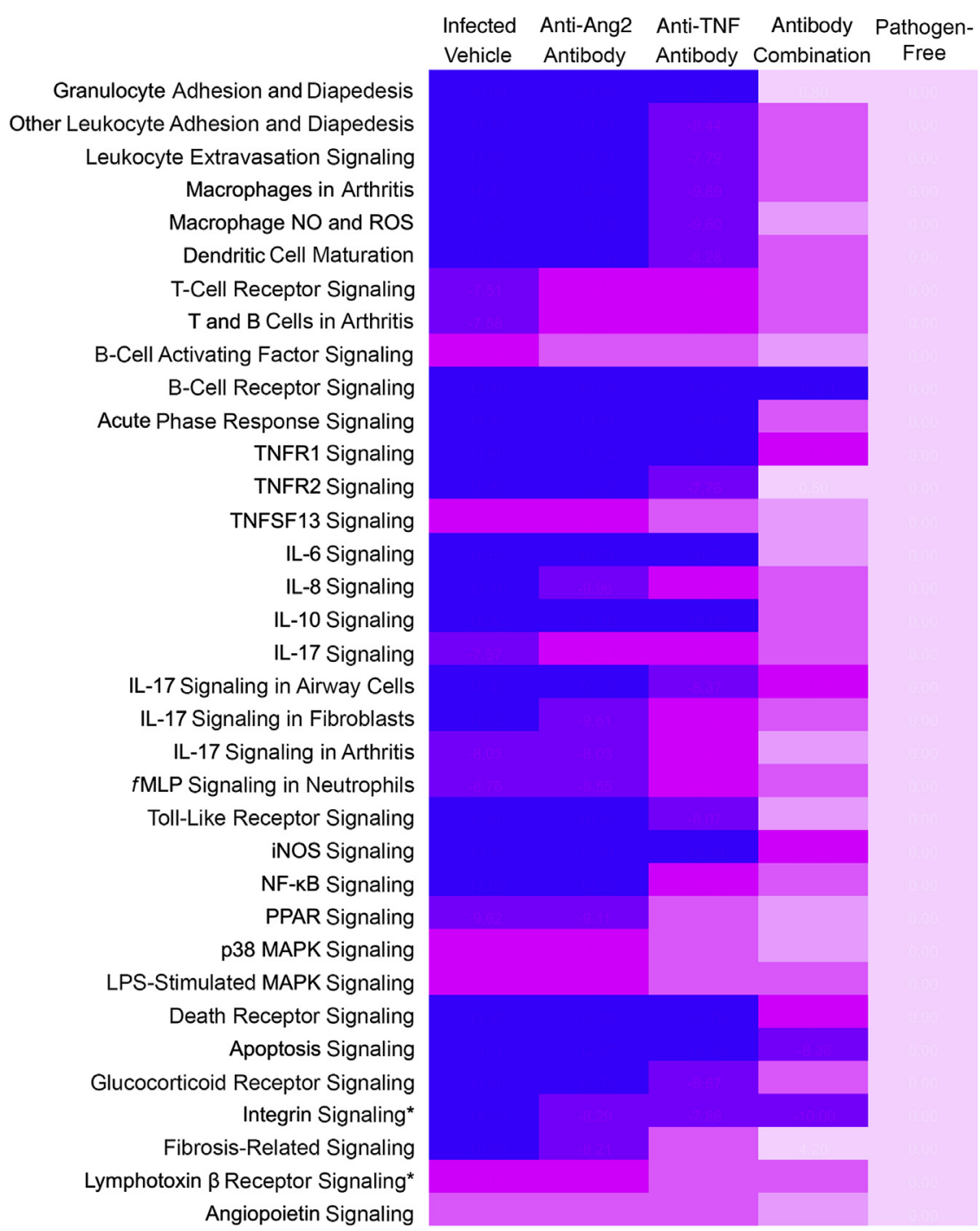

Color Code: Log10 $P$-Value of Difference from Pathogen Free $<-10 \quad-10<-7.5 \quad-7.5<-5 \quad-5<-2.5 \quad-2.5<0 \quad \geq 0$
Figure 6 Heat map of treatment suppression of pathways activated by infection. Functional grouping that compares amounts of treatment suppression of canonical pathways that were activated during Mycoplasma pulmonis infection (7 days) (condition A). The infected group treated with vehicle has the highest values (purple-blue), and the pathogen-free group has the lowest values (pink). Pathways, assessed by Ingenuity Pathway Analysis, are the same as shown in Table 4. The three treatment columns show relative efficacy, color coded as the difference between $\log 10$ of $P$ value for the infected vehicle group and $\log 10$ of $P$ value for the corresponding treatment. Treatment efficacy is reflected in the shift from purple-blue toward pink, where lighter colors indicate smaller differences from the pathogen-free baseline. Each step from purple-blue to pink indicates a $10^{2.5}$-fold change in the $P$ value for the treatment-related suppression of pathway activity. For all but two of these pathways (asterisks), the antibody combination reduced the activity closer to the baseline than the other treatments. $P$ values calculated by Fisher's exact text are corrected for false positives by using the Benjamini-Hochberg procedure. Ang2, angiopoietin-2; fMLP, N-formyl-Met-Leu-Phe; iNOS, inducible NO synthase; MAPK, mitogen-activated protein kinase; N0, nitric oxide; PPAR, peroxisome proliferator-activated receptor; ROS, reactive oxygen species; TNF, tumor necrosis factor; TNFR, TNF receptor; TNFSF, TNF superfamily.

\section{Suppression of Neutrophil Influx by Inhibition of Ang2 and TNF Together}

The initial phase of vascular remodeling after M. pulmonis infection is dependent on and proportional to the influx of neutrophils. ${ }^{45}$ Ang2 and TNF contribute to the recruitment of these cells. TNF blockade during M. pulmonis infection reduces leukocyte influx into the lung, ${ }^{20}$ and Ang2 blockade reduces CD11b-positive cell recruitment into the airway mucosa. ${ }^{5}$ Ang2-null mice have impaired neutrophil recruitment to sites of inflammation. ${ }^{3,28}$ We found that inhibition of Ang2 and TNF together resulted in greater attenuation of neutrophil recruitment and expression of neutrophil-related proteins and chemoattractants (eg, S100a8, S100a9, and C-X-C chemokines) than inhibition of either one alone. The antibody combination also had greater effects on vascular remodeling, leakage, P-selectin staining, and pericyte changes in the remodeled vessels and was accompanied by significantly lower expression of $\mathrm{Cxcll}$ and IL-1 $\beta$. Overexpression of IL- $1 \beta$ leads to recruitment of neutrophils and macrophages, growth of lymphatics, and up-regulation of expression of $S 100 a 9$ and $C x c l l$ mRNA. ${ }^{46}$ Mice lacking Cxcr2, the receptor for Cxcll, have less vascular remodeling and less neutrophil influx. ${ }^{8,45}$

Expression of P-selectin and E-selectin was strongly increased during M. pulmonis infection. The increase of both was suppressed by blocking Ang2 or TNF and was reduced even more by the antibody combination (P-selectin, 83\%; E-selectin, 91\%). Both selectins contribute to neutrophil adherence and migration in mice, but their regulation and respective roles differ in mice and humans. ${ }^{55,56} \mathrm{TNF}$ increases P-selectin in murine, but not human, endothelial cells, where E-selectin is more important for leukocyte recruitment. ${ }^{55}$ In the context of M. pulmonis infection in mice, where the antibody 


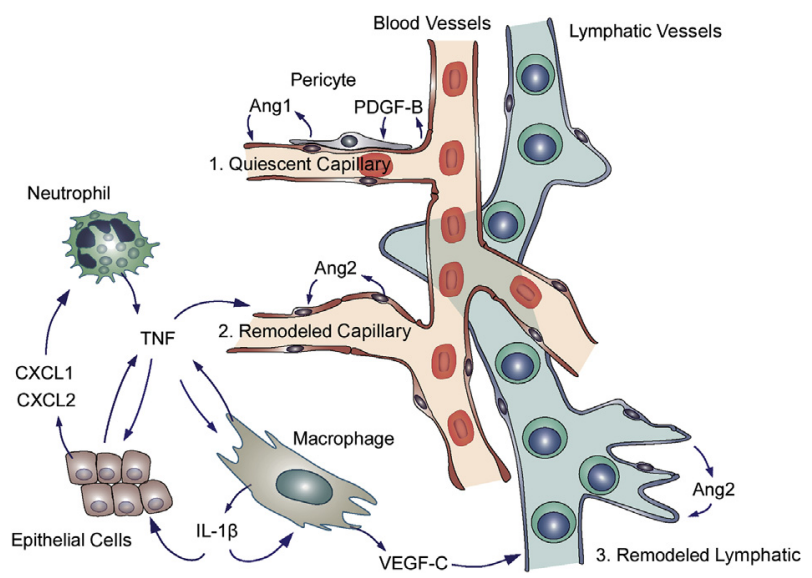

Figure 7 Synergistic actions of angiopoietin-2 (Ang2) and tumor necrosis factor (TNF) in vascular remodeling in inflammation. Schematic drawing of the complementary contributions of Ang2 and TNF to remodeling of blood vessels and lymphatics in the airway mucosa after Mycoplasma pulmonis infection. The drawing illustrates some of the factors that contribute to the actions of the two cytokines on the inflammatory response. 1: Under pathogen-free conditions, Ang1-driven phosphorylation of Tie2 receptors in endothelial cells helps maintain quiescence of the vasculature. Quiescent endothelial cells release platelet-derived growth factor B (PDGF-B) that contributes to vascular stability through actions on pericytes, which are a source of Ang1. 2: In sustained inflammation, Ang2 from endothelial cells suppresses Tie2 phosphorylation and signaling. TNF from activated neutrophils, macrophages, and other cells activates endothelial cells. ${ }^{20}$ Through synergistic actions on endothelial cells, Ang2 and TNF promote vascular remodeling manifested by capillary enlargement and acquisition of a venular phenotype. These changes are accompanied by pericyte detachment, vessel leakiness, adhesion molecule expression, and leukocyte influx (data not shown). Cxcl1 and Cxcl2 from epithelial cells and other cytokines trigger leukocyte recruitment. ${ }^{45} 3$ : IL-1 $\beta$ from macrophages and other cells contributes to the release of chemokines that recruit VEGF-C-producing macrophages. ${ }^{46}$ Ang2 from lymphatic endothelial cells promotes lymphatic sprouting, ${ }^{13,14}$ after sensitization by VEGF-C and other cytokines from TNF-activated macrophages. ${ }^{16,47}$

combination suppressed but did not stop neutrophil influx, multiple chemokines and adhesion molecules contribute to leukocyte recruitment. ${ }^{45}$ With treatment, significant reductions in expression were found not only in P-selectin and E-selectin, but also in Icaml and the chemoattractant ligands and receptors Cxcll, Cxcl2, and Cxcr2.

Because of the emphasis of the present study on the initial changes after M. pulmonis infection, neutrophils were used as an index of the cellular inflammatory response. Macrophages, dendritic cells, and $\mathrm{T}$ and $\mathrm{B}$ lymphocytes become abundant in the trachea and lung of mice after infection, but not as rapidly as neutrophils. ${ }^{8,9,45}$ By 14 days, macrophages and lymphocytes are widespread in bronchial-associated lymphoid tissue. ${ }^{9}$

Inhibition of TNF during M. pulmonis infection did not impair survival during the first 7 days, but thereafter was accompanied by higher mortality. The importance of TNF in contributing to resistance to infection is well documented. ${ }^{37,38,57}$ TNF can play an essential role in protective immunity by modulating inflammatory cytokine release from macrophages and T-cell-mediated protection in infections. ${ }^{37,38}$ Inhibition of TNF can increase the risk of infection by numerous opportunistic pathogens. ${ }^{26}$ Mortality of some anti-TNF-treated mice after the first week of infection is consistent with the greater importance of the cytokine for survival during the second week. Therefore, the present experiments focused on the phase of rapid blood vessel remodeling and lymphatic sprouting during the first week after infection.

\section{Mechanism of Synergistic Actions of Ang2 and TNF}

Ang2 and TNF induce vascular remodeling and lymphatic sprouting through multiple synergistic mechanisms (Figure 7). Ang2, as an antagonist of Tie2 receptors, competitively inhibits Ang1-mediated Tie2 phosphorylation. ${ }^{4,5,12}$ Through this action, Ang2 promotes endothelial cell destabilization, pericyte detachment, and proinflammatory effects. ${ }^{12,58}$ In addition to these direct actions, Ang2 sensitizes endothelial cells to TNF and increases the effects of TNF on adhesion molecule expression, leukocyte adherence, leakage, and angiogenesis. ${ }^{28,29,59,60}$ In the presence of Ang2, lower concentrations of TNF promote expression of Icaml, Vcam1, and E-selectin and leukocyte rolling and adhesion. Ang2, like Ang1, greatly amplifies TNF-driven cytokine release from Tie2-positive macrophages and suppresses production of the angiogenesis inhibitor, thrombospondin2, but has weak direct effects on these cells. ${ }^{30,31,61}$ These Ang2 effects contribute to the inflammatory response in arthritis models. ${ }^{31}$ Sensitization by Ang2 is not limited to TNF, as initially shown by Ang2 promotion of VEGFinduced angiogenesis. ${ }^{62,63}$

To extend the mechanistic understanding of the synergy between Ang2 and TNF in promoting inflammation, we compared the effects of inhibiting Ang2, TNF, and both together on genome-wide changes in gene expression during M. pulmonis infection. Expression of $>7000$ genes changed $>25 \%$ during infection. Changes in $>2000$ of these genes were modified $50 \%$ or more by treatment. Inhibition of Ang2 and TNF together had the largest and most widespread effects. Expression of the 100 genes that increased most during infection (6- to 324-fold) was reduced by $73 \%$, on average, by treatment with the antibody combination. In evidence of synergy, this suppression was $57 \%$ greater than the sum of the corresponding reductions, resulting from the antibodies given individually.

Functional analysis by IPA of infection-driven pathway activation revealed larger effects of the antibody combination on many inflammatory processes. Among these were suppression of leukocyte influx, cytokine activity, and NF$\kappa \mathrm{B}$ signaling. TNF increases Ang2 expression in endothelial cells through activation of NF- $\kappa \mathrm{B}$ signaling. ${ }^{27}$ Inhibition of Ang2 leads to Tie2 activation, which, in turn, suppresses $\mathrm{NF}-\kappa \mathrm{B}$ signaling and reduces TNF-induced inflammatory actions involving NF- $\kappa \mathrm{B}-$ responsive genes. ${ }^{64,65}$

In summary, this study revealed that inhibition of Ang2 and TNF, given together, completely prevented the remodeling of 
blood vessels and lymphatic sprouting during the first week of M. pulmonis infection. Readouts included remodeling of endothelial cells and pericytes, leukocyte recruitment, lymphatic sprouting, and genome-wide GeneChip analysis, which revealed broad treatment-induced suppression of genes activated during infection. Striking features of the effects of blocking Ang2 and TNF together were the magnitude and breadth of the changes. The antibody combination suppressed the expression of $>1000$ genes, and indicative of synergy, had effects that were significantly greater than the sum of the individual blockers. Many pathways activated by infection were suppressed more by the antibody combination than by either antibody given alone. These findings implicate Ang2 and TNF as synergistic drivers of vascular remodeling and lymphatic sprouting in the initial phase of inflammation in this model. Because Ang2 and TNF promote endothelial cell activation and remodeling, leukocyte influx, and macrophage cytokine release, they both influence the context and activity of the other. Further studies are necessary to fully dissect the synergistic actions of Ang2 and TNF and the range of conditions that can be prevented or reversed by inhibiting them together.

\section{Acknowledgments}

We thank Oishee Bose and Peter Baluk for preparing stocks of Mycoplasma pulmonis and Peter Baluk, Minah Kim, and Li-Chin Yao for their helpful discussions throughout the project.

C.T.K.L., G.L., J.R.C., and D.M.McD. designed the experiments and wrote the manuscript. C.T.K.L. and G.L. performed mouse experiments. C.A.M., B.N., and P.B. performed the array profiling of gene expression. C.T.K.L., G.L., C.A.M., B.N., P.B., J.R.C., and D.M.McD. analyzed the data. C.T.K.L. and T.M. composed Figure 7.

\section{Supplemental Data}

Supplemental material for this article can be found at http://dx.doi.org/10.1016/j.ajpath.2015.07.010.

\section{References}

1. Wilson JW, Hii S: The importance of the airway microvasculature in asthma. Curr Opin Allergy Clin Immunol 2006, 6:51-55

2. Kunstfeld R, Hirakawa S, Hong YK, Schacht V, LangeAsschenfeldt B, Velasco P, Lin C, Fiebiger E, Wei X, Wu Y, Hicklin D, Bohlen P, Detmar M: Induction of cutaneous delayed-type hypersensitivity reactions in VEGF-A transgenic mice results in chronic skin inflammation associated with persistent lymphatic hyperplasia. Blood 2004, 104:1048-1057

3. Ganta VC, Cromer W, Mills GL, Traylor J, Jennings M, Daley S, Clark B, Mathis JM, Bernas M, Boktor M, Jordan P, Witte M, Alexander JS: Angiopoietin-2 in experimental colitis. Inflamm Bowel Dis 2010, 16:1029-1039

4. Fuxe J, Lashnits E, O’Brien S, Baluk P, Tabruyn SP, Kuhnert F, Kuo C, Thurston G, McDonald DM: Angiopoietin/Tie2 signaling transforms capillaries into venules primed for leukocyte trafficking in airway inflammation. Am J Pathol 2010, 176:2009-2018

5. Tabruyn SP, Colton K, Morisada T, Fuxe J, Wiegand SJ, Thurston G, Coyle AJ, Connor J, McDonald DM: Angiopoietin-2-driven vascular remodeling in airway inflammation. Am J Pathol 2010, 177: 3233-3243

6. Baluk P, Tammela T, Ator E, Lyubynska N, Achen MG, Hicklin DJ, Jeltsch M, Petrova TV, Pytowski B, Stacker SA, Yla-Herttuala S, Jackson DG, Alitalo K, McDonald DM: Pathogenesis of persistent lymphatic vessel hyperplasia in chronic airway inflammation. J Clin Invest 2005, 115:247-257

7. Fuxe J, Tabruyn S, Colton K, Zaid H, Adams A, Baluk P, Lashnits E, Morisada T, Le T, O'Brien S, Epstein DM, Koh GY, McDonald DM Pericyte requirement for anti-leak action of angiopoietin-1 and vascular remodeling in sustained inflammation. Am J Pathol 2011, 178:2897-2909

8. Yao LC, Baluk P, Feng J, McDonald DM: Steroid-resistant lymphatic remodeling in chronically inflamed mouse airways. Am J Pathol 2010, 176:1525-1541

9. Baluk P, Adams A, Phillips K, Feng J, Hong YK, Brown MB, McDonald DM: Preferential lymphatic growth in bronchus-associated lymphoid tissue in sustained lung inflammation. Am J Pathol 2014, 184:1577-1592

10. McDonald DM: Angiogenesis and remodeling of airway vasculature in chronic inflammation. Am J Respir Crit Care Med 2001, 164: S39-S45

11. Martin RJ: Infections and asthma. Clin Chest Med 2006, 27:87-98. vi

12. Maisonpierre PC, Suri C, Jones PF, Bartunkova S, Wiegand SJ, Radziejewski C, Compton D, McClain J, Aldrich TH, Papadopoulos N, Daly TJ, Davis S, Sato TN, Yancopoulos GD: Angiopoietin-2, a natural antagonist for Tie2 that disrupts in vivo angiogenesis. Science 1997, 277:55-60

13. Gale NW, Thurston G, Hackett SF, Renard R, Wang Q, McClain J, Martin C, Witte C, Witte MH, Jackson D, Suri C, Campochiaro PA, Wiegand SJ, Yancopoulos GD: Angiopoietin-2 is required for postnatal angiogenesis and lymphatic patterning, and only the latter role is rescued by Angiopoietin-1. Dev Cell 2002, 3:411-423

14. Dellinger $M$, Hunter $R$, Bernas $M$, Gale $N$, Yancopoulos $G$, Erickson R, Witte M: Defective remodeling and maturation of the lymphatic vasculature in Angiopoietin-2 deficient mice. Dev Biol 2008, 319:309-320

15. Zheng W, Nurmi H, Appak S, Sabine A, Bovay E, Korhonen EA, Orsenigo F, Lohela M, D'Amico G, Holopainen T, Leow CC, Dejana E, Petrova TV, Augustin HG, Alitalo K: Angiopoietin 2 regulates the transformation and integrity of lymphatic endothelial cell junctions. Genes Dev 2014, 28:1592-1603

16. Yan ZX, Jiang ZH, Liu NF: Angiopoietin-2 promotes inflammatory lymphangiogenesis and its effect can be blocked by the specific inhibitor L1-10. Am J Physiol Heart Circ Physiol 2012, 302: $\mathrm{H} 215-\mathrm{H} 223$

17. Holopainen T, Saharinen P, D'Amico G, Lampinen A, Eklund L, Sormunen R, Anisimov A, Zarkada G, Lohela M, Helotera H, Tammela T, Benjamin LE, Yla-Herttuala S, Leow CC, Koh GY, Alitalo K: Effects of angiopoietin-2-blocking antibody on endothelial cell-cell junctions and lung metastasis. J Natl Cancer Inst 2012, 104: 461-475

18. Pfister F, Wang Y, Schreiter K, vom Hagen F, Altvater K, Hoffmann S, Deutsch U, Hammes HP, Feng Y: Retinal overexpression of angiopoietin-2 mimics diabetic retinopathy and enhances vascular damages in hyperglycemia. Acta Diabetol 2010, 47:59-64

19. Parikh SM, Mammoto T, Schultz A, Yuan HT, Christiani D, Karumanchi SA, Sukhatme VP: Excess circulating angiopoietin-2 may contribute to pulmonary vascular leak in sepsis in humans. PLoS Med 2006, 3:e46

20. Baluk P, Yao LC, Feng J, Romano T, Jung SS, Schreiter JL, Yan L, Shealy DJ, McDonald DM: TNF-alpha drives remodeling of blood 
vessels and lymphatics in sustained airway inflammation in mice. J Clin Invest 2009, 119:2954-2964

21. Tigges U, Boroujerdi A, Welser-Alves JV, Milner R: TNF-alpha promotes cerebral pericyte remodeling in vitro, via a switch from alpha1 to alpha2 integrins. J Neuroinflammation 2013, 10:33

22. Viemann D, Goebeler M, Schmid S, Klimmek K, Sorg C, Ludwig S, Roth J: Transcriptional profiling of IKK2/NF-kappa B- and p38 MAP kinase-dependent gene expression in TNF-alpha-stimulated primary human endothelial cells. Blood 2004, 103:3365-3373

23. Li P, Schwarz EM: The TNF-alpha transgenic mouse model of inflammatory arthritis. Springer Semin Immunopathol 2003, 25:19-33

24. Silva LC, Ortigosa LC, Benard G: Anti-TNF-alpha agents in the treatment of immune-mediated inflammatory diseases: mechanisms of action and pitfalls. Immunotherapy 2010, 2:817-833

25. Van Hauwermeiren F, Vandenbroucke RE, Libert C: Treatment of TNF mediated diseases by selective inhibition of soluble TNF or TNFR1. Cytokine Growth Factor Rev 2011, 22:311-319

26. Rosenblum H, Amital H: Anti-TNF therapy: safety aspects of taking the risk. Autoimmun Rev 2011, 10:563-568

27. Kim I, Kim JH, Ryu YS, Liu M, Koh GY: Tumor necrosis factoralpha upregulates angiopoietin-2 in human umbilical vein endothelial cells. Biochem Biophys Res Commun 2000, 269:361-365

28. Fiedler U, Reiss Y, Scharpfenecker M, Grunow V, Koidl S, Thurston G, Gale NW, Witzenrath M, Rosseau S, Suttorp N, Sobke A, Herrmann M, Preissner KT, Vajkoczy P, Augustin HG: Angiopoietin-2 sensitizes endothelial cells to TNF-alpha and has a crucial role in the induction of inflammation. Nat Med 2006, 12: 235-239

29. Chen JX, Chen Y, DeBusk L, Lin W, Lin PC: Dual functional roles of Tie-2/angiopoietin in TNF-alpha-mediated angiogenesis. Am J Physiol Heart Circ Physiol 2004, 287:H187-H195

30. Garcia S, Krausz S, Ambarus CA, Fernandez BM, Hartkamp LM, van Es IE, Hamann J, Baeten DL, Tak PP, Reedquist KA: Tie2 signaling cooperates with TNF to promote the pro-inflammatory activation of human macrophages independently of macrophage functional phenotype. PLoS One 2014, 9:e82088

31. Krausz S, Garcia S, Ambarus CA, de Launay D, Foster M, Naiman B, Iverson W, Connor JR, Sleeman MA, Coyle AJ, Hamann J, Baeten D, Tak PP, Reedquist KA: Angiopoietin-2 promotes inflammatory activation of human macrophages and is essential for murine experimental arthritis. Ann Rheum Dis 2012, 71:1402-1410

32. Kanakaraj P, Puffer BA, Yao XT, Kankanala S, Boyd E, Shah RR, Wang G, Patel D, Krishnamurthy R, Kaithamana S, Smith RG, LaFleur DW, Barbas CF 3rd, Hilbert DM, Kiener PA, Roschke VV: Simultaneous targeting of TNF and Ang2 with a novel bispecific antibody enhances efficacy in an in vivo model of arthritis. MAbs 2012, 4:600-613

33. McCall MN, Bolstad BM, Irizarry RA: Frozen robust multiarray analysis (fRMA). Biostatistics 2010, 11:242-253

34. Kramer A, Green J, Pollard J Jr, Tugendreich S: Causal analysis approaches in Ingenuity Pathway Analysis. Bioinformatics 2014, 30: $523-530$

35. Huang DW, Sherman BT, Lempicki RA: Systematic and integrative analysis of large gene lists using DAVID bioinformatics resources. Nat Protoc 2009, 4:44-57

36. Brown JL, Cao ZA, Pinzon-Ortiz M, Kendrew J, Reimer C, Wen S, Zhou JQ, Tabrizi M, Emery S, McDermott B, Pablo L, McCoon P, Bedian V, Blakey DC: A human monoclonal anti-ANG2 antibody leads to broad antitumor activity in combination with VEGF inhibitors and chemotherapy agents in preclinical models. Mol Cancer Ther 2010, 9:145-156

37. Deepe GS Jr, Gibbons RS: T cells require tumor necrosis factor-alpha to provide protective immunity in mice infected with Histoplasma capsulatum. J Infect Dis 2006, 193:322-330

38. Algood HM, Lin PL, Yankura D, Jones A, Chan J, Flynn JL: TNF influences chemokine expression of macrophages in vitro and that of
$\mathrm{CD} 11 \mathrm{~b}+$ cells in vivo during Mycobacterium tuberculosis infection. J Immunol 2004, 172:6846-6857

39. Baffert F, Le T, Thurston G, McDonald DM: Angiopoietin-1 decreases plasma leakage by reducing number and size of endothelial gaps in venules. Am J Physiol Heart Circ Physiol 2006, 290: H107-H118

40. Baluk P, Hirata A, Thurston G, Fujiwara T, Neal CR, Michel CC, McDonald DM: Endothelial gaps: time course of formation and closure in inflamed venules of rats. Am J Physiol 1997, 272: L155-L170

41. McDonald DM, Thurston G, Baluk P: Endothelial gaps as sites for plasma leakage in inflammation. Microcirculation 1999, 6:7-22

42. von Tell D, Armulik A, Betsholtz C: Pericytes and vascular stability. Exp Cell Res 2006, 312:623-629

43. Feng Y, vom Hagen F, Pfister F, Djokic S, Hoffmann S, Back W, Wagner P, Lin J, Deutsch U, Hammes HP: Impaired pericyte recruitment and abnormal retinal angiogenesis as a result of angiopoietin-2 overexpression. Thromb Haemost 2007, 97:99-108

44. Ribatti D, Nico B, Crivellato E: The role of pericytes in angiogenesis. Int J Dev Biol 2011, 55:261-268

45. Baluk P, Phillips K, Yao LC, Adams A, Nitschke M, McDonald DM: Neutrophil dependence of vascular remodeling after Mycoplasma infection of mouse airways. Am J Pathol 2014, 184:1877-1889

46. Baluk P, Hogmalm A, Bry M, Alitalo K, Bry K, McDonald DM: Transgenic overexpression of interleukin-1beta induces persistent lymphangiogenesis but not angiogenesis in mouse airways. Am J Pathol 2013, 182:1434-1447

47. Ristimaki A, Narko K, Enholm B, Joukov V, Alitalo K: Proinflammatory cytokines regulate expression of the lymphatic endothelial mitogen vascular endothelial growth factor-C. J Biol Chem 1998, 273:8413-8418

48. Cai J, Kehoe O, Smith GM, Hykin P, Boulton ME: The angiopoietin/Tie-2 system regulates pericyte survival and recruitment in diabetic retinopathy. Invest Ophthalmol Vis Sci 2008, 49: $2163-2171$

49. Rock JR, Barkauskas CE, Cronce MJ, Xue Y, Harris JR, Liang J, Noble PW, Hogan BL: Multiple stromal populations contribute to pulmonary fibrosis without evidence for epithelial to mesenchymal transition. Proc Natl Acad Sci U S A 2011, 108:E1475-E1483

50. Baluk P, Fuxe J, Hashizume H, Romano T, Lashnits E, Butz S, Vestweber D, Corada M, Molendini C, Dejana E, McDonald DM: Functionally specialized junctions between endothelial cells of lymphatic vessels. J Exp Med 2007, 204:2349-2362

51. Yao LC, Baluk P, Srinivasan RS, Oliver G, McDonald DM: Plasticity of button-like junctions in the endothelium of airway lymphatics in development and inflammation. Am J Pathol 2012, 180:2561-2575

52. Watari K, Nakao S, Fotovati A, Basaki Y, Hosoi F, Bereczky B, Higuchi R, Miyamoto T, Kuwano M, Ono M: Role of macrophages in inflammatory lymphangiogenesis: enhanced production of vascular endothelial growth factor C and D through NF-kappaB activation. Biochem Biophys Res Commun 2008, 377:826-831

53. Tammela T, Alitalo K: Lymphangiogenesis: molecular mechanisms and future promise. Cell 2010, 140:460-476

54. Maruyama K, Asai J, Ii M, Thorne T, Losordo DW, D'Amore PA: Decreased macrophage number and activation lead to reduced lymphatic vessel formation and contribute to impaired diabetic wound healing. Am J Pathol 2007, 170:1178-1191

55. Liu Z, Miner JJ, Yago T, Yao L, Lupu F, Xia L, McEver RP: Differential regulation of human and murine P-selectin expression and function in vivo. J Exp Med 2010, 207:2975-2987

56. Yao L, Setiadi H, Xia L, Laszik Z, Taylor FB, McEver RP: Divergent inducible expression of P-selectin and E-selectin in mice and primates. Blood 1999, 94:3820-3828

57. Mohan VP, Scanga CA, Yu K, Scott HM, Tanaka KE, Tsang E, Tsai MM, Flynn JL, Chan J: Effects of tumor necrosis factor alpha on host immune response in chronic persistent tuberculosis: possible role for limiting pathology. Infect Immun 2001, 69:1847-1855 
58. Thurston G, Rudge JS, Ioffe E, Papadopoulos N, Daly C, Vuthoori S, Daly T, Wiegand SJ, Yancopoulos GD: The anti-inflammatory actions of angiopoietin-1. EXS 2005, (94):233-245

59. Mangan SH, Van Campenhout A, Rush C, Golledge J: Osteoprotegerin upregulates endothelial cell adhesion molecule response to tumor necrosis factor-alpha associated with induction of angiopoietin2. Cardiovasc Res 2007, 76:494-505

60. Benest AV, Kruse K, Savant S, Thomas M, Laib AM, Loos EK, Fiedler U, Augustin HG: Angiopoietin-2 is critical for cytokineinduced vascular leakage. PLoS One 2013, 8:e70459

61. Coffelt SB, Chen YY, Muthana M, Welford AF, Tal AO, Scholz A, Plate KH, Reiss Y, Murdoch C, De Palma M, Lewis CE: Angiopoietin 2 stimulates TIE2-expressing monocytes to suppress $\mathrm{T}$ cell activation and to promote regulatory $\mathrm{T}$ cell expansion. $\mathrm{J}$ Immunol 2011, 186:4183-4190
62. Holash J, Wiegand SJ, Yancopoulos GD: New model of tumor angiogenesis: dynamic balance between vessel regression and growth mediated by angiopoietins and VEGF. Oncogene 1999, 18: $5356-5362$

63. Visconti RP, Richardson CD, Sato TN: Orchestration of angiogenesis and arteriovenous contribution by angiopoietins and vascular endothelial growth factor (VEGF). Proc Natl Acad Sci U S A 2002, 99: $8219-8224$

64. He DK, Shao YR, Zhang L, Shen J, Zhong ZY, Wang J, Xu G: Adenovirus-delivered angiopoietin-1 suppresses NF-kappaB and p38 MAPK and attenuates inflammatory responses in phosgene-induced acute lung injury. Inhal Toxicol 2014, 26:185-192

65. Hughes DP, Marron MB, Brindle NP: The antiinflammatory endothelial tyrosine kinase Tie2 interacts with a novel nuclear factorkappaB inhibitor ABIN-2. Circ Res 2003, 92:630-636 